\title{
Widespread and persistent invasions of terrestrial habitats coincident with larval feeding behavior transitions during snail-killing fly evolution (Diptera: Sciomyzidae)
}

Eric G Chapman ${ }^{1}$, Andrey A Przhiboro², James D Harwood ${ }^{1}$, Benjamin A Foote ${ }^{3}$ and Walter R Hoeh ${ }^{3 *}$

\begin{abstract}
Background: Transitions in habitats and feeding behaviors were fundamental to the diversification of life on Earth. There is ongoing debate regarding the typical directionality of transitions between aquatic and terrestrial habitats and the mechanisms responsible for the preponderance of terrestrial to aquatic transitions. Snail-killing flies (Diptera: Sciomyzidae) represent an excellent model system to study such transitions because their larvae display a range of feeding behaviors, being predators, parasitoids or saprophages of a variety of mollusks in freshwater, shoreline and dry terrestrial habitats. The remarkable genus Tetanocera (Tetanocerini) occupies five larval feeding groups and all of the habitat types mentioned above. This study has four principal objectives: (i) construct a robust estimate of phylogeny for Tetanocera and Tetanocerini, (ii) estimate the evolutionary transitions in larval feeding behaviors and habitats, (iii) test the monophyly of feeding groups and (iv) identify mechanisms underlying sciomyzid habitat and feeding behavior evolution.
\end{abstract}

Results: Bayesian inference and maximum likelihood analyses of molecular data provided strong support that the Sciomyzini, Tetanocerini and Tetanocera are monophyletic. However, the monophyly of many behavioral groupings was rejected via phylogenetic constraint analyses. We determined that (i) the ancestral sciomyzid lineage was terrestrial, (ii) there was a single terrestrial to aquatic habitat transition early in the evolution of the Tetanocerini and (iii) there were at least 10 independent aquatic to terrestrial habitat transitions and at least 15 feeding behavior transitions during tetanocerine phylogenesis. The ancestor of Tetanocera was aquatic with five lineages making independent transitions to terrestrial habitats and seven making independent transitions in feeding behaviors.

Conclusions: The preponderance of aquatic to terrestrial transitions in sciomyzids goes against the trend generally observed across eukaryotes. Damp shoreline habitats are likely transitional where larvae can change habitat but still have similar prey available. Transitioning from aquatic to terrestrial habitats is likely easier than the reverse for sciomyzids because morphological characters associated with air-breathing while under the water's surface are lost rather than gained, and sciomyzids originated and diversified during a general drying period in Earth's history. Our results imply that any animal lineage having aquatic and terrestrial members, respiring the same way in both habitats and having the same type of food available in both habitats could show a similar pattern of multiple independent habitat transitions coincident with changes in behavioral and morphological traits.

\footnotetext{
* Correspondence: whoeh@kent.edu

${ }^{3}$ Evolutionary, Population, and Systematic Biology Group, Department of Biological Sciences, Cunningham Hall, Kent State University, Kent, OH 44242 , USA

Full list of author information is available at the end of the article
}

\section{Biomed Central}

(c) 2012 Chapman et al.; licensee BioMed Central Ltd. This is an Open Access article distributed under the terms of the Creative Commons Attribution License (http://creativecommons.org/licenses/by/2.0), which permits unrestricted use, distribution, and reproduction in any medium, provided the original work is properly cited. 


\section{Background}

Some of the most important evolutionary innovations in the history of life on Earth resulted from transitions between aquatic (freshwater) and terrestrial habitats. The colonization of land by unicellular aquatic plants $[1,2]$ and their eventual transformation into vascular plants helped shape terrestrial environments and paved the way for the evolution of the majority of the eukaryotic species alive today. Other key lineage diversifications that occurred following transitions from aquatic to terrestrial habitats include those of tetrapod vertebrates [3], millipedes [4], scorpions [5], other arachnids [2,6,7], earth worms [8] and nematodes [9]. Whereas the ancestral insect originated in a terrestrial environment [10-12], insects are one of the most successful colonizers of freshwater habitats, as at least 12 of the 31 insect orders have representatives occupying these environments during at least one life history stage [13]. Transitions between aquatic and terrestrial habitats are generally rarer than other habitat changes (e.g., between epigeal and arboreal) because of the substantial physical differences between them [14]. In addition to differences in the physical requirements of living in water versus on land (e.g., differences in oxygen concentration), one presumed barrier is that the suite of available food items are typically distinct, as there are major differences between aquatic and terrestrial food webs $[15,16]$. Therefore, in order to transition between these habitats, a lineage typically must adapt to new physical conditions while concomitantly modifying its feeding behaviors.

The family Sciomyzidae, or "snail-killing flies" (Diptera: Acalyptratae: Sciomyzoidea), is an ideal taxon with which to study the evolution of feeding behaviors and associated habitat transitions. Their life histories are well-studied, as 240 of the 539 species have known larval feeding habits [17]. Sciomyzid larvae display a wide range of feeding behaviors, including predation, parasitism, or saprophagy of terrestrial, semi-aquatic and aquatic non-operculate snails, operculate aquatic snails, semi-terrestrial succineid snails, slugs, snail eggs, fingernail clams and freshwater oligochaete worms $[17,18]$. This represents, by far, the most extensive radiation of primarily malacophagous (= mollusk-feeding) species when compared to all other dipteran lineages [17,18]. A total of 109 species from six other dipteran families attack mollusks [19], whereas $\sim 99 \%$ of the 240 sciomyzid species with known life cycles attack mollusks $[17,18,20]$. Sciomyzids have three larval stages and most species exhibiting parasitoid behavior have very specific host requirements in the $1^{\text {st }}$ and $2^{\text {nd }}$ larval stage but become more generalized predators in the $3^{\text {rd }}$ stage. These species have been referred to as parasitoids or parasitoids/predators in sciomyzid literature, so, for simplicity, we refer to these species as parasitoids herein. There have been two different approaches to organizing sciomyzid species into behavioral/ecological groups: (i) based on commonalities in larval microhabitat, mode of feeding and prey type ([21]: 8 groups; [22]: 10 groups; [20]: 9 groups; [17,18]: 15 groups), and (ii) based on an ordination analysis of 36 egg and larval morphological characters, larval behaviors, and habitat that identified nine "Eco-Groups," each possessing a unique combination of states from these 36 characters [23].

The Sciomyzidae includes three subfamilies: the Huttonininae with two genera [24], the Salticellinae with one genus (Salticella) and the Sciomyzinae with the remaining 58 genera. The Sciomyzinae is comprised of two tribes, the Sciomyzini with 12 genera and the Tetanocerini with the remaining 46 genera [17]. All of the Sciomyzini and Salticellinae have terrestrial larvae, whereas 14 tetanocerine genera have at least one species with aquatic larvae [17]. The larvae of the Huttonininae remain unknown [17]. Recent phylogenetic analyses of morphological data suggest that the Sciomyzinae and its two tribes are monophyletic $[23,25]$. The family Phaeomyiidae, with five described Palaearctic species in two genera (Akebono and Pelidnoptera), was at one time considered to be a subfamily of the Sciomyzidae, but was subsequently elevated to family by Griffiths [26], who proposed its sister status to Sciomyzidae.

The evolution of feeding behaviors in Sciomyzidae has been discussed in numerous papers (e.g., [17,18,20-22]). Because larval feeding on decaying animal matter occurs in other dipteran lineages, including families in the Sciomyzoidea (e.g., Dryomyzidae; [17]), it has been suggested that the ancestral sciomyzid was probably similar to the extant Atrichomelina pubera (Sciomyzini), a generalist that feeds on dead, dying or living aquatic and semi-aquatic, non-operculate snails on damp terrestrial substrates [27,28]. Steyskal's [29] classification of the Sciomyzidae lead to sciomyzine larvae being characterized as terrestrial (including those inhabiting moist surfaces) saprophages/predators/parasitoids, while tetanocerine larvae are typically characterized as aquatic predators. Knutson \& Vala [18] mapped their feeding groups onto the morphological phylogeny presented in Marinoni \& Mathis [25] to infer the ancestral feeding behavior for the family and to discuss the evolution of such behaviors based on the position of each genus in the phylogeny. They concluded that while Steyskal's [29] generalizations have exceptions, the distribution of feeding behaviors known today support these general characterizations. They further concluded that the terrestrial habits of many of the species in the Tetanocerini represent a derived condition within the tribe. Unfortunately, the utility of Knutson and Vala's [18] study was somewhat limited due to the incomplete resolution of intergeneric relationships and the absence of replicate 
Table 1 Species analyzed in this study, the feeding behavioral group [17] to which each taxon belongs, and GenBank numbers for the sequences used in this

\section{study}

\begin{tabular}{|c|c|c|c|c|c|c|c|c|c|}
\hline \multirow{2}{*}{$\begin{array}{c}\text { Family } \\
\text { Tribe }\end{array}$} & \multirow{2}{*}{$\begin{array}{l}\text { Genus } \\
\text { Species }\end{array}$} & \multirow{2}{*}{$\begin{array}{l}\text { Feeding Group } \\
\text { Feeding Group }\end{array}$} & \multirow{2}{*}{$\begin{array}{l}\text { Specimen } \\
\text { Citation }\end{array}$} & \multicolumn{5}{|c|}{ GenBank Accession Numbers } & \multirow[b]{2}{*}{ Ef-1a } \\
\hline & & & & Number & $\mathrm{COI}$ & COII & $16 S$ & $28 \mathrm{~S}$ & \\
\hline Drosophilidae & $\begin{array}{l}\text { Drosophila melanogaster } \\
\text { Meigen } 1830\end{array}$ & Yeast, mold & [80] & & AJ400907 & AJ400907 & AJ400907 & M21017 & NM_170570 \\
\hline Phaeomyiidae & $\begin{array}{l}\text { Pelidnoptera nigripennis } \\
\text { (Fabricius 1794) }\end{array}$ & Millipede parasitoid & [81] & $F 272$ & JN860439 & & & JN837497 & JN816249 \\
\hline \multicolumn{10}{|l|}{ Sciomyzidae } \\
\hline \multirow[t]{5}{*}{ Sciomyzini } & Atrichomelina & & & & & & & & \\
\hline & $\begin{array}{l}\text { Atrichomelina pubera } \\
\text { (Loew 1862) }\end{array}$ & $\begin{array}{l}\text { Facultative predator/ } \\
\text { saprophage of snails } \\
\text { and clams on } \\
\text { damp shorelines }\end{array}$ & [28] & F160 & JN860438 & JN837567 & JN816281 & JN837498 & \\
\hline & & & & F161 & AY875151 & AY875182 & AY875089 & AY875120 & JN816247 \\
\hline & Sciomyza & & & & & & & & \\
\hline & $\begin{array}{l}\text { Sciomyza simplex } \\
\text { Fallén } 1820\end{array}$ & $\begin{array}{l}\text { Predator of shoreline- } \\
\text { stranded aquatics }\end{array}$ & [82] & F175 & AY875152 & AY875183 & AY875090 & AY875121 & JN816248 \\
\hline \multirow[t]{14}{*}{ Tetanocerini } & Anticheta & & & & & & & & \\
\hline & $\begin{array}{l}\text { Anticheta melanosoma } \\
\text { Melander } 1920\end{array}$ & $\begin{array}{l}\text { Predator of exposed } \\
\text { snail eggs }\end{array}$ & [83] & F254 & JN860440 & JN837568 & JN816327 & JN837499 & JN816250 \\
\hline & Dichetophora & & & & & & & & \\
\hline & $\begin{array}{l}\text { Dichetophora finlandica } \\
\text { Verbèke } 1964\end{array}$ & Unknown & & $F 248$ & JN860441 & JN837569 & JN816328 & JN837500 & JN816251 \\
\hline & Dictya & & & & & & & & \\
\hline & $\begin{array}{l}\text { Dictya borealis } \\
\text { Curran } 1932\end{array}$ & $\begin{array}{l}\text { Predator of aquatic } \\
\text { snails in the water }\end{array}$ & [84] & $F 257$ & JN860442 & JN837570 & JN816329 & JN837501 & JN816252 \\
\hline & $\begin{array}{l}\text { Dictya expansa } \\
\text { Steyskal } 1938\end{array}$ & $\begin{array}{l}\text { Predator of aquatic } \\
\text { snails in the water }\end{array}$ & [84] & F263 & JN860443 & JN837571 & JN816330 & JN837502 & \\
\hline & $\begin{array}{l}\text { Dictya floridensis } \\
\text { Steyskal } 1954\end{array}$ & $\begin{array}{l}\text { Predator of aquatic } \\
\text { snails in the water }\end{array}$ & {$[85]$} & F258 & JN860444 & JN837572 & JN816331 & JN837503 & \\
\hline & $\begin{array}{l}\text { Dictya gaigei } \\
\text { Steyskal } 1938\end{array}$ & $\begin{array}{l}\text { Predator of aquatic } \\
\text { snails in the water }\end{array}$ & [84] & F267 & JN860445 & JN837573 & JN816336 & JN837504 & \\
\hline & $\begin{array}{l}\text { Dictya pictipes } \\
\text { (Loew 1859) }\end{array}$ & $\begin{array}{l}\text { Predator of aquatic } \\
\text { snails in the water }\end{array}$ & [84] & F261 & JN860446 & JN837574 & JN816332 & JN837505 & JN816253 \\
\hline & $\begin{array}{l}\text { Dictya steyskali } \\
\text { Valley } 1977\end{array}$ & $\begin{array}{l}\text { Predator of aquatic } \\
\text { snails in the water }\end{array}$ & {$[84]$} & $F 270$ & JN860447 & JN837575 & JN816333 & JN837506 & \\
\hline & & & & $F 271$ & JN860448 & JN837576 & JN816334 & JN837507 & JN816254 \\
\hline & $\begin{array}{l}\text { Dictya stricta } \\
\text { Steyskal } 1938\end{array}$ & $\begin{array}{l}\text { Predator of aquatic } \\
\text { snails in the water }\end{array}$ & [84] & $F 260$ & JN860449 & JN837577 & & JN837508 & \\
\hline & $\begin{array}{l}\text { Dictya texensis } \\
\text { Curran } 1932\end{array}$ & $\begin{array}{l}\text { Predator of aquatic } \\
\text { snails in the water }\end{array}$ & [84] & F268 & JN860450 & JN837578 & JN816335 & JN837509 & \\
\hline
\end{tabular}


Table 1 Species analyzed in this study, the feeding behavioral group [17] to which each taxon belongs, and GenBank numbers for the sequences used in this study (Continued)

\begin{tabular}{|c|c|c|c|c|c|c|c|c|}
\hline \multicolumn{9}{|l|}{ Dictyacium } \\
\hline $\begin{array}{l}\text { Dictyacium firmum } \\
\text { Steyskal } 1956\end{array}$ & Unknown & & F187 & JN860451 & JN837579 & JN816337 & JN837510 & \\
\hline & & & F188 & JN860452 & JN837580 & JN816338 & JN837511 & \\
\hline \multicolumn{9}{|l|}{ Elgiva } \\
\hline $\begin{array}{l}\text { Elgiva connexa } \\
\text { Steyskal } 1954\end{array}$ & $\begin{array}{l}\text { Predator of aquatic } \\
\text { snails in the water }\end{array}$ & [86] & F150 & AY875153 & AY875184 & AY875091 & AY875122 & \\
\hline & & & F151 & JN860453 & JN837581 & JN816282 & JN837512 & \\
\hline & & & F152 & JN860454 & JN837582 & JN816283 & JN837513 & JN816255 \\
\hline $\begin{array}{l}\text { Elgiva solicita } \\
\text { (Harris 1780) }\end{array}$ & $\begin{array}{l}\text { Predator of aquatic } \\
\text { snails in the water }\end{array}$ & [86] & F5 & AY875154 & AY875185 & AY875092 & AY875123 & \\
\hline & & & F6 & JN860455 & JN837583 & JN816284 & JN837514 & \\
\hline \multicolumn{9}{|l|}{ Ethiolimnia } \\
\hline $\begin{array}{l}\text { Ethiolimnia geniculata } \\
\text { (Loew 1862) }\end{array}$ & Unknown & & F255 & JN860456 & JN837584 & JN816339 & JN837515 & JN816256 \\
\hline \multicolumn{9}{|l|}{ Euthycera } \\
\hline $\begin{array}{l}\text { Euthycera arcuata } \\
\text { (Loew 1859) }\end{array}$ & $\begin{array}{l}\text { Parasitoid of } \\
\text { slugs }\end{array}$ & [87] & F222 & JN860457 & JN837585 & JN816340 & & JN816257 \\
\hline & & & F223 & JN860458 & JN837586 & JN816341 & JN837516 & \\
\hline & & & F224 & JN860459 & JN837587 & JN816342 & JN837517 & \\
\hline \multicolumn{9}{|l|}{ Hedria } \\
\hline $\begin{array}{l}\text { Hedria mixta } \\
\text { Steyskal } 1954\end{array}$ & $\begin{array}{l}\text { Predator of submerged } \\
\text { aquatic snails }\end{array}$ & [88] & F168 & JN860460 & JN837588 & JN816285 & JN837518 & \\
\hline & & & F169 & AY875155 & AY875186 & AY875093 & AY875124 & \\
\hline \multicolumn{9}{|l|}{ Hoplodictya } \\
\hline $\begin{array}{l}\text { Hoplodictya acuticornis } \\
\text { (Wulp 1897) }\end{array}$ & $\begin{array}{l}\text { Parasitoid of } \\
\text { succineid snails }\end{array}$ & $\begin{array}{l}\text { LV Knutson } \\
\text { (pers. comm.) }\end{array}$ & F277 & JN860461 & JN837589 & JN816343 & JN837519 & JN816258 \\
\hline & & & F278 & JN860462 & JN837590 & JN816344 & JN837520 & \\
\hline \multicolumn{9}{|l|}{ Hydromya } \\
\hline $\begin{array}{l}\text { Hydromya dorsalis } \\
\text { (Fabricius 1775) }\end{array}$ & $\begin{array}{l}\text { Predator of shoreline- } \\
\text { stranded aquatics }\end{array}$ & [89] & $F 249$ & JN860463 & JN837591 & JN816345 & JN837521 & JN816259 \\
\hline Ilione & & [90] & & & & & & \\
\hline $\begin{array}{l}\text { Ilione albiseta } \\
\text { (Scopoli 1763) }\end{array}$ & $\begin{array}{l}\text { Predator of submerged } \\
\text { aquatic snails }\end{array}$ & {$[91,92]$} & F122 & JN860464 & JN837592 & JN816286 & & \\
\hline \multicolumn{9}{|l|}{ Limnia } \\
\hline $\begin{array}{l}\text { Limnia boscii Robineau- } \\
\text { Desvoidy } 1830\end{array}$ & $\begin{array}{l}\text { Parasitoid of } \\
\text { succineid snails }\end{array}$ & $\begin{array}{l}\text { LV Knutson } \\
\text { (pers. comm.) }\end{array}$ & F120 & AY875156 & AY875187 & AY875094 & AY875125 & JN816260 \\
\hline & & & F121 & JN860465 & JN837593 & JN816287 & JN837522 & \\
\hline
\end{tabular}


Table 1 Species analyzed in this study, the feeding behavioral group [17] to which each taxon belongs, and GenBank numbers for the sequences used in this study (Continued)

\begin{tabular}{|c|c|c|c|c|c|c|c|c|}
\hline $\begin{array}{l}\text { Limnia ottawensis } \\
\text { Melander } 1920\end{array}$ & Unknown & & F154 & AY875157 & AY875188 & AY875095 & AY875126 & JN816261 \\
\hline $\begin{array}{l}\text { Limnia sandovalensis } \\
\text { Fisher \& Orth } 1978\end{array}$ & Unknown & & F155 & AY875158 & AY875189 & AY875096 & AY875127 & \\
\hline & & & F156 & JN860466 & JN837594 & JN816288 & JN837523 & \\
\hline Pherbecta & & & & & & & & \\
\hline $\begin{array}{l}\text { Pherbecta limenitis } \\
\text { Steyskal } 1956\end{array}$ & Unknown & & F237 & JN860467 & JN837595 & JN816346 & JN837524 & JN816262 \\
\hline Pherbina & & & & & & & & \\
\hline $\begin{array}{l}\text { Pherbina coryleti } \\
\text { (Scopoli 1763) }\end{array}$ & $\begin{array}{l}\text { Predator of shoreline- } \\
\text { stranded aquatics }\end{array}$ & {$[37]$} & $F 250$ & JN860468 & JN837596 & JN816347 & & \\
\hline Poecilographa & & & & & & & & \\
\hline $\begin{array}{l}\text { Poecilographa decora } \\
\text { (Loew 1864) }\end{array}$ & Unknown & & F212 & JN860469 & JN837597 & JN816348 & JN837525 & JN816263 \\
\hline & & & F230 & JN860470 & JN837598 & JN816349 & JN837526 & \\
\hline Psacadina & & & & & & & & \\
\hline $\begin{array}{l}\text { Psacadina zernyi } \\
\text { (Mayer 1953) }\end{array}$ & $\begin{array}{l}\text { Predator of shoreline- } \\
\text { stranded aquatics }\end{array}$ & {$[37]$} & $F 251$ & JN860471 & & JN816350 & JN837527 & JN816264 \\
\hline Renocera & & & & & & & & \\
\hline $\begin{array}{l}\text { Renocera amanda } \\
\text { (Cresson 1920) }\end{array}$ & $\begin{array}{l}\text { Parasitoid of fingernail } \\
\text { clams below the water's } \\
\text { surface }\end{array}$ & [93] & F88 & AY875159 & AY875190 & AY875097 & AY875128 & \\
\hline $\begin{array}{l}\text { Renocera johnsoni } \\
\text { (Cresson 1920) }\end{array}$ & $\begin{array}{l}\text { Predator of aquatic } \\
\text { snails in the water }\end{array}$ & $\begin{array}{l}\text { BA Foote } \\
\text { (unpublished) }\end{array}$ & F90 & AY875160 & AY875191 & AY875098 & AY875129 & \\
\hline & & & F92 & JN860472 & JN837599 & JN816289 & JN837528 & JN816265 \\
\hline $\begin{array}{l}\text { Renocera pallida } \\
\text { (Fallen 1820) }\end{array}$ & $\begin{array}{l}\text { Parasitoid of fingernail } \\
\text { clams above the water's } \\
\text { surface }\end{array}$ & [94] & F193 & JN860473 & JN837600 & JN816351 & JN837529 & \\
\hline & & & F194 & JN860474 & JN837601 & JN816352 & JN837530 & JN816266 \\
\hline Sepedon & & & & & & & & \\
\hline $\begin{array}{l}\text { Sepedon armipes } \\
\text { Loew } 1859\end{array}$ & $\begin{array}{l}\text { Predator of aquatic } \\
\text { snails in the water }\end{array}$ & [95] & F28 & AY875161 & AY875192 & AY875099 & AY875130 & \\
\hline $\begin{array}{l}\text { Sepedon fuscipennis } \\
\text { Loew } 1859\end{array}$ & Unknown & & F116 & JN860475 & JN837602 & JN816360 & & \\
\hline & & & F117 & AY875162 & AY875193 & AY875100 & AY875131 & \\
\hline $\begin{array}{l}\text { Sepedon praemiosa } \\
\text { Giglio-Tos } 1893\end{array}$ & $\begin{array}{l}\text { Predator of aquatic } \\
\text { snails in the water }\end{array}$ & [95] & F118 & AY875163 & AY875194 & AY875101 & AY875132 & JN816267 \\
\hline Tetanocera & & & & & & & & \\
\hline $\begin{array}{l}\text { Tetanocera amurensis } \\
\text { Hendel } 1809\end{array}$ & Unknown & & F198 & JN860478 & JN837605 & JN816290 & JN837533 & \\
\hline
\end{tabular}


Table 1 Species analyzed in this study, the feeding behavioral group [17] to which each taxon belongs, and GenBank numbers for the sequences used in this study (Continued)

\begin{tabular}{|c|c|c|c|c|c|c|c|c|}
\hline & & & F199 & JN860479 & JN837606 & JN816291 & JN837534 & \\
\hline & & & F200 & JN860480 & JN837607 & JN816292 & & \\
\hline $\begin{array}{l}\text { Tetanocera annae } \\
\text { Steyskal } 1938\end{array}$ & $\begin{array}{l}\text { Predator of aquatic } \\
\text { snails in the water }\end{array}$ & [96] & F201 & JN860481 & JN837608 & JN816293 & & JN816270 \\
\hline & & & F202 & JN860482 & JN837609 & JN816294 & & \\
\hline & & & F229 & JN860483 & JN837610 & JN816319 & JN837535 & \\
\hline $\begin{array}{l}\text { Tetanocera arnaudi } \\
\text { Orth \& Fisher } 1982\end{array}$ & Unknown & & F23 & JN860484 & JN837611 & JN816295 & JN837536 & \\
\hline & & & F24 & JN860485 & JN837612 & JN816296 & JN837537 & \\
\hline $\begin{array}{l}\text { Tetanocera arrogans } \\
\text { Meigen } 1830\end{array}$ & $\begin{array}{l}\text { Parasitoid of } \\
\text { succineid snails }\end{array}$ & [39] & F93 & AY875165 & AY875196 & AY875103 & AY875134 & JN816271 \\
\hline $\begin{array}{l}\text { Tetanocera bergi } \\
\text { Steyskal } 1954\end{array}$ & $\begin{array}{l}\text { Predator of aquatic } \\
\text { snails in the water }\end{array}$ & [73] & F159 & JN860486 & & JN816297 & JN837538 & JN816272 \\
\hline $\begin{array}{l}\text { Tetanocera clara } \\
\text { Loew } 1862\end{array}$ & $\begin{array}{l}\text { Parasitoid of } \\
\text { slugs }\end{array}$ & {$[97,98]$} & F57 & AY875167 & AY875198 & AY875105 & AY875136 & JN816273 \\
\hline $\begin{array}{l}\text { Tetanocera elata } \\
\text { (Fabricius 1781) }\end{array}$ & $\begin{array}{l}\text { Parasitoid of } \\
\text { slugs }\end{array}$ & [99] & F245 & JN860487 & JN837613 & JN816298 & JN837539 & \\
\hline & & & F247 & JN860488 & JN837614 & JN816299 & JN837540 & \\
\hline $\begin{array}{l}\text { Tetanocera ferruginea } \\
\text { Fallén } 1820\end{array}$ & $\begin{array}{l}\text { Predator of aquatic } \\
\text { snails in the water }\end{array}$ & [96] & F34 & AY875168 & AY875199 & AY875106 & AY875137 & \\
\hline & & & F158 & AY875166 & AY875197 & AY875104 & AY875135 & \\
\hline $\begin{array}{l}\text { Tetanocera freyi } \\
\text { Stackelberg } 1963\end{array}$ & Unknown & & F203 & JN860489 & JN837615 & JN816300 & & JN816274 \\
\hline $\begin{array}{l}\text { Tetanocera fuscinervis } \\
\text { (Zetterstedt 1838) }\end{array}$ & $\begin{array}{l}\text { Predator of shoreline- } \\
\text { stranded aquatics }\end{array}$ & [100] & F53 & AY875169 & AY875200 & AY875107 & AY875138 & \\
\hline & & & F54 & JN860490 & JN837616 & JN816302 & JN837541 & \\
\hline & & & F153 & JN860491 & JN837617 & JN816301 & JN837542 & \\
\hline $\begin{array}{l}\text { Tetanocera hyalipennis } \\
\text { Roser } 1840\end{array}$ & $\begin{array}{l}\text { Predator of shoreline- } \\
\text { stranded aquatics }\end{array}$ & [39] & F127 & JN860492 & JN837618 & JN816303 & & \\
\hline & & & F191 & JN860493 & JN837619 & JN816304 & JN837543 & \\
\hline & & & F192 & JN860494 & JN837620 & JN816305 & JN837544 & \\
\hline $\begin{array}{l}\text { Tetanocera kerteszi } \\
\text { Hendel } 1901\end{array}$ & $\begin{array}{l}\text { Predator of } \\
\text { terrestrial snails }\end{array}$ & $\begin{array}{l}\text { LV Knutson } \\
\text { (pers. comm.) }\end{array}$ & F46 & AY875170 & AY875201 & AY875108 & AY875139 & \\
\hline & & & F47 & JN860495 & JN837621 & JN816306 & JN837545 & \\
\hline $\begin{array}{l}\text { Tetanocera latifibula } \\
\text { Frey } 1924\end{array}$ & $\begin{array}{l}\text { Predator of aquatic } \\
\text { snails in the water }\end{array}$ & [96] & F144 & JN860496 & JN837622 & JN816357 & JN837546 & \\
\hline & & & F146 & JN860497 & JN837623 & JN816358 & JN837547 & \\
\hline & & & F147 & AY875171 & AY875202 & AY875109 & AY875140 & \\
\hline & & & F149 & JN860498 & JN837624 & JN816359 & JN837548 & \\
\hline
\end{tabular}


Table 1 Species analyzed in this study, the feeding behavioral group [17] to which each taxon belongs, and GenBank numbers for the sequences used in this study (Continued)

\begin{tabular}{|c|c|c|c|c|c|c|c|c|}
\hline $\begin{array}{l}\text { Tetanocera loewi } \\
\text { Steyskal } 1959\end{array}$ & $\begin{array}{l}\text { Predator of aquatic } \\
\text { snails in the water }\end{array}$ & [96] & F189 & JN860499 & JN837625 & JN816307 & JN837549 & \\
\hline & & & F226 & JN860500 & JN837626 & JN816308 & JN837550 & \\
\hline $\begin{array}{l}\text { Tetanocera melanostigma } \\
\text { Steyskal } 1959\end{array}$ & $\begin{array}{l}\text { Parasitoid of } \\
\text { succineid snails }\end{array}$ & [101] & $\mathrm{F} 2$ & AY875172 & AY875203 & AY875110 & AY875141 & \\
\hline $\begin{array}{l}\text { Tetanocera mesopora } \\
\text { Steyskal } 1959\end{array}$ & $\begin{array}{l}\text { Predator of aquatic } \\
\text { snails in the water }\end{array}$ & [96] & F40 & AY875173 & AY875204 & AY875111 & AY875142 & \\
\hline $\begin{array}{l}\text { Tetanocera montana } \\
\text { Day } 1881\end{array}$ & $\begin{array}{l}\text { Predator of aquatic } \\
\text { snails in the water }\end{array}$ & [96] & F142 & AY875174 & AY875205 & AY875112 & AY875143 & \\
\hline & & & F143 & JN860501 & JN837627 & JN816309 & JN837551 & \\
\hline & & & F170 & JN860502 & JN837628 & JN816310 & JN837552 & \\
\hline & & & F171 & JN860503 & JN837629 & JN816311 & JN837553 & JN816275 \\
\hline $\begin{array}{l}\text { Tetanocera obtusifibula } \\
\text { Melander } 1920\end{array}$ & $\begin{array}{l}\text { Predator of aquatic } \\
\text { snails in the water }\end{array}$ & [96] & $F 275$ & JN860504 & JN837630 & JN816353 & JN837554 & \\
\hline & & & F276 & JN860505 & JN837631 & JN816354 & JN837555 & \\
\hline $\begin{array}{l}\text { Tetanocera oxia } \\
\text { Steyskal } 1959\end{array}$ & $\begin{array}{l}\text { Parasitoid of } \\
\text { succineid snails }\end{array}$ & [101] & F204 & JN860506 & JN837632 & JN816312 & & \\
\hline $\begin{array}{l}\text { Tetanocera phyllophora } \\
\text { Melander } 1920\end{array}$ & $\begin{array}{l}\text { Predator of } \\
\text { terrestrial snails }\end{array}$ & {$[98,102]$} & F39 & AY875175 & AY875206 & AY875113 & AY875144 & \\
\hline $\begin{array}{l}\text { Tetanocera plebeja } \\
\text { Loew } 1862\end{array}$ & $\begin{array}{l}\text { Parasitoid of } \\
\text { slugs }\end{array}$ & {$[97,98]$} & F1 & JN860507 & JN837633 & JN816314 & JN837556 & \\
\hline & & & F13 & AY875176 & AY875207 & AY875114 & AY875145 & \\
\hline & & & F205 & JN860508 & JN837634 & JN816313 & & JN816276 \\
\hline $\begin{array}{l}\text { Tetanocera plumosa } \\
\text { Loew } 1847\end{array}$ & $\begin{array}{l}\text { Predator of aquatic } \\
\text { snails in the water or } \\
\text { on damp shorelines }\end{array}$ & [73] & F11 & AY875177 & AY875208 & AY875115 & AY875146 & \\
\hline & & & F43 & JN860509 & JN837635 & & JN837557 & \\
\hline $\begin{array}{l}\text { Tetanocera robusta } \\
\text { Loew } 1847\end{array}$ & $\begin{array}{l}\text { Predator of aquatic } \\
\text { snails in the water }\end{array}$ & [96] & F10 & AY875178 & AY875209 & AY875116 & AY875147 & \\
\hline & & & F16 & JN860510 & JN837636 & JN816317 & JN837558 & \\
\hline & & & F134 & JN860511 & JN837637 & JN816315 & JN837559 & JN816277 \\
\hline & & & F137 & JN860512 & JN837638 & JN816316 & JN837560 & \\
\hline $\begin{array}{l}\text { Tetanocera rotundicornis } \\
\text { Loew } 1861\end{array}$ & $\begin{array}{l}\text { Parasitoid of } \\
\text { succineid snails }\end{array}$ & [101] & F206 & JN860513 & JN837639 & JN816318 & JN837561 & \\
\hline $\begin{array}{l}\text { Tetanocera silvatica } \\
\text { Meigen } 1830\end{array}$ & $\begin{array}{l}\text { Predator of shoreline- } \\
\text { stranded aquatics }\end{array}$ & [100] & F35 & JN860515 & & JN816321 & JN837562 & JN816279 \\
\hline & & & F172 & AY875179 & AY875210 & AY875117 & AY875148 & JN816278 \\
\hline & & & F173 & JN860514 & JN837640 & JN816320 & JN837563 & \\
\hline & & [103] & F209 & JN860516 & JN837641 & JN816322 & & \\
\hline
\end{tabular}


Table 1 Species analyzed in this study, the feeding behavioral group [17] to which each taxon belongs, and GenBank numbers for the sequences used in this study (Continued)

\begin{tabular}{|c|c|c|c|c|c|c|c|c|c|}
\hline & $\begin{array}{l}\text { Tetanocera soror } \\
\text { Melander } 1920\end{array}$ & $\begin{array}{l}\text { Predator of aquatic } \\
\text { snails in the water }\end{array}$ & & & & & & & \\
\hline & & & & F210 & JN860517 & JN837642 & JN816323 & & \\
\hline & $\begin{array}{l}\text { Tetanocera valida } \\
\text { Loew } 1862\end{array}$ & Parasitoid of slugs & {$[97,98]$} & F84 & AY875180 & AY875211 & AY875118 & AY875149 & JN816280 \\
\hline & $\begin{array}{l}\text { Tetanocera vicina } \\
\text { Macquart } 1843\end{array}$ & $\begin{array}{l}\text { Predator of aquatic } \\
\text { snails in the water }\end{array}$ & [96] & F94 & AY875181 & AY875212 & AY875119 & AY875150 & \\
\hline & & & & F95 & JN860518 & JN837643 & JN816324 & JN837564 & \\
\hline & & & & F98 & JN860519 & JN837644 & JN816325 & JN837565 & \\
\hline & & & & F99 & JN860520 & JN837645 & JN816326 & JN837566 & \\
\hline & Trypetoptera & & & & & & & & \\
\hline & $\begin{array}{l}\text { Trypetoptera canadensis } \\
\text { (Macquart 1843) }\end{array}$ & $\begin{array}{l}\text { Predator of } \\
\text { terrestrial snails }\end{array}$ & $\begin{array}{l}\text { BA Foote } \\
\text { (unpublished) }\end{array}$ & F164 & AY875164 & AY875195 & AY875102 & AY875133 & JN816268 \\
\hline $\begin{array}{l}\text { Trypetoptera punctulata } \\
\text { (Scopoli 1763) }\end{array}$ & $\begin{array}{l}\text { Predator of } \\
\text { terrestrial snails }\end{array}$ & & [104] & F217 & JN860476 & JN837603 & JN816355 & JN837531 & JN816269 \\
\hline & & & & F218 & JN860477 & JN837604 & JN816356 & JN837532 & \\
\hline Sequence coverage & & & & \multicolumn{2}{|c|}{ out of 114 OTUs } & \multicolumn{2}{|c|}{ out of 65 species } & \multicolumn{2}{|c|}{ out of 23 genera } \\
\hline $\mathrm{COI}$ & & & & \multicolumn{2}{|c|}{ 114: $100 \%$} & \multicolumn{2}{|l|}{ 65: $100 \%$} & \multicolumn{2}{|l|}{ 23: $100 \%$} \\
\hline COII & & & & \multicolumn{2}{|c|}{ 110: $96.5 \%$} & \multicolumn{2}{|l|}{ 62: $95.4 \%$} & \multicolumn{2}{|l|}{ 21: $91.3 \%$} \\
\hline $16 S$ & & & & \multicolumn{2}{|c|}{ 111: $97.4 \%$} & \multicolumn{2}{|l|}{ 63: 96.9\% } & \multicolumn{2}{|l|}{ 22: 95.6\% } \\
\hline 285 & & & & \multicolumn{2}{|c|}{ 101: $88.6 \%$} & \multicolumn{2}{|l|}{ 60: $92.3 \%$} & \multicolumn{2}{|l|}{ 21: $91.3 \%$} \\
\hline EF1a & & & & \multicolumn{2}{|c|}{$34: 29.8 \%$} & \multicolumn{2}{|l|}{$33: 50.8 \%$} & \multicolumn{2}{|l|}{ 19: 82.6\% } \\
\hline
\end{tabular}


intrageneric taxon sampling within the Marinoni \& Mathis [25] phylogeny. A more recent study on intergeneric sciomyzid relationships [23], which included more morphological characters than did Marinoni \& Mathis [25], was similarly limited, as the taxon sampling was nearly identical and the relationships among many of the genera not well-supported. Therefore, a wellresolved species-level phylogeny focusing on a lineage that exhibits a variety of feeding behaviors and occupies multiple habitats would enable a better understanding of the evolutionary processes involved in transitions among habitat, mode of feeding and host/prey selection.

Within the Tetanocerini, the genus Tetanocera is of particular interest because it is one of the most diverse sciomyzid genera with respect to feeding behaviors. Twenty-eight of its 39 species have known life cycles (see Table 1 for a partial list) and its species occupy five of the 15 feeding groups of Knutson \& Vala [17,18]: $(i)$ general predators of non-operculate aquatic snails in the water (14 species), (ii) general predators of nonoperculate aquatic snails occurring on damp shorelines (3 species), (iii) general predators of terrestrial snails (2 species), (iv) parasitoids of slugs (4 species) or ( $v$ ) parasitoids of succineid (semi-terrestrial) snails (5 species). The life cycles of 11 species remain unknown. Members of the largest feeding group within Tetanocera ( $i$ above) spend their larval stages just under the surface of the water, whereas the remaining groups have terrestrial larvae. Only one other sciomyzid genus occupies five feeding groups (Sepedon), whereas most only occupy one or two [17].

In a previous paper, a DNA sequence-based phylogeny of sciomyzids was used to examine the evolution of larval characters that appeared correlated with larval habitat [30]. Character states in four larval characters were found to be significantly correlated with aquatic to terrestrial transitions in Tetanocera where each larval character changed in the same way as multiple lineages made independent habitat transitions. In the present study, we build on these findings by examining feeding behavior evolution, as feeding behaviors are dependent on both larval morphological adaptations to different environments and specific requirements related to finding and subduing different prey species. Given the diversity of feeding behaviors within Sciomyzidae and Tetanocera, it is important to determine whether there were single or multiple origins of feeding behaviors. Such an analysis would simultaneously show whether there was convergent evolution of larval habitat and the relative frequencies of habitat transitions. Multiple evolutionary hypotheses regarding feeding behaviors and habitat transitions are presented in the literature (e.g., $[17,18,20,21,23,27-29])$ and all should be considered plausible until rigorously evaluated using modern phylogenetic comparative methods. Therefore, the present study has four specific objectives: $(i)$ construct a robust estimate of phylogeny for Tetanocera and Tetanocerini based on multiple mitochondrial and nuclear genes, (ii) estimate the evolutionary transitions in larval feeding behaviors, habitats and host/prey that have occurred during the evolution of Tetanocerini and Tetanocera, (iii) test prior hypotheses regarding the monophyly of feeding and ecological groupings and (iv) identify the mechanisms underlying habitat and feeding behavior evolution in Tetanocera.

\section{Results}

\section{Phylogenetic analyses}

We used Bayesian inference (BI) and maximum likelihood (ML) to analyze a concatenated 5-gene data set. The BI MAP tree with BI posterior probabilities (x100) and ML bootstrap nodal support values is shown in Figure 1. The BI MAP and best ML tree (Additional file 1: Figure S1) were largely congruent (also see Additional file 1: Figure S2, Additional file 1: Figure S3 for BI consensus and ML bootstrap trees, respectively). Both recovered a monophyletic Tetanocerini $(\mathrm{BI} P \mathrm{PP}=1.0$; $\mathrm{ML}$ bootstrap $=100)$, a monophyletic Sciomyzini $(\mathrm{PP}=1.0$; BS $=100$ ), and placed Pelidnoptera, now in Phaeomyiidae but once considered a subfamily of Sciomyzidae (e.g., [31]) as the sister lineage to the Tetanocerini, suggesting its potential status as a tribe within the Sciomyzinae $(\mathrm{PP}=0.97 ; \mathrm{BS}=80$; Figure 1). All genera with multiple species are monophyletic except for (1) Limnia, which is rendered polyphyletic by Trypetoptera and Pherbina in the BI MAP tree and by Trypetoptera in the best ML tree, (2) Trypetoptera, rendered polyphyletic by Limnia ottawensis in both trees and (3) Renocera, rendered polyphyletic by Ethiolimnia and Dichetophora in both trees. The polyphyly of these genera are each supported by at least one node with high BI PP and ML BS values (Figure 1).

Both BI and ML recovered a monophyletic Tetanocera $(\mathrm{PP}=1.0 ; \mathrm{BS}=96$; Figure 1). Within Tetanocera, both trees have $T$. robusta $+T$. annae (Figures 1,2,3: clade (1) as sister to the remaining species. Both analyses recovered Tetanocera clade (2) (Figures 1,2,3) with identical relationships. This clade includes all five behavioral groups known for the genus (Table 1; Figure 2). The other major Tetanocera clade common to both trees (Figures 1,2,3: clade (3) contains eight aquatic predators, one shoreline predator, one terrestrial predator and two species with unknown life cycles, with relatively minor differences in species relationships between the BI and ML trees. Finally, both analyses recovered $T$. silvatica + T. freyi (Figures 1,2,3: clade (4)) as sister species: in the BI MAP tree, clade (4) is sister to clade (2) + clade (3), however in the best ML tree, clade (4) is sister to clade (3) 


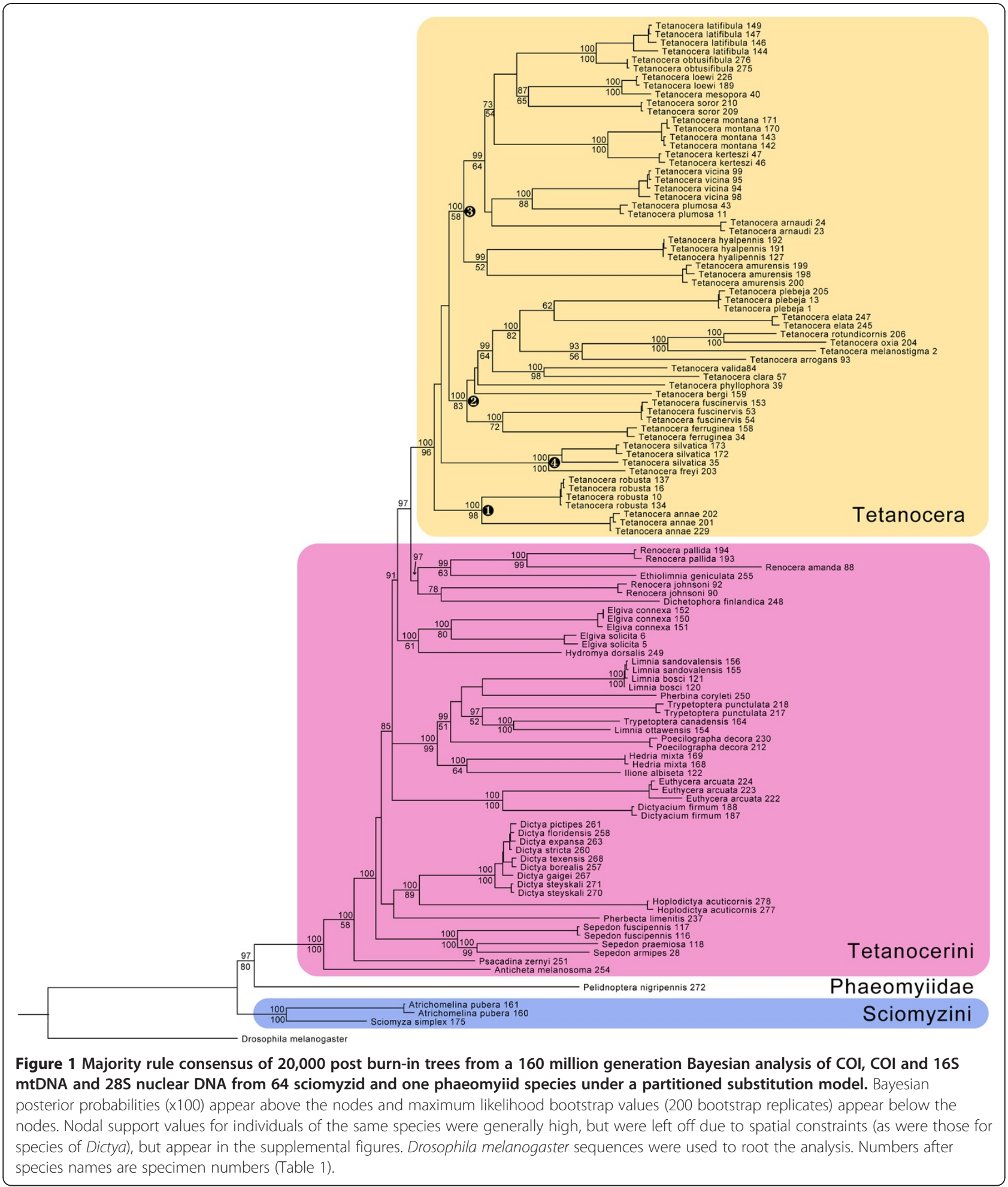

(Additional file 1: Figure S1). The BI MAP and best ML trees were not significantly different from one another as judged by ML methods via GARLI and CONSEL (Table 2).

\section{Behavioral group optimizations}

We optimized Knutson and Vala's [17] larval behavioral groups on the BI MAP tree using ML methods in Mesquite (Figure 2; see Additional file 1: Figure S4 for 


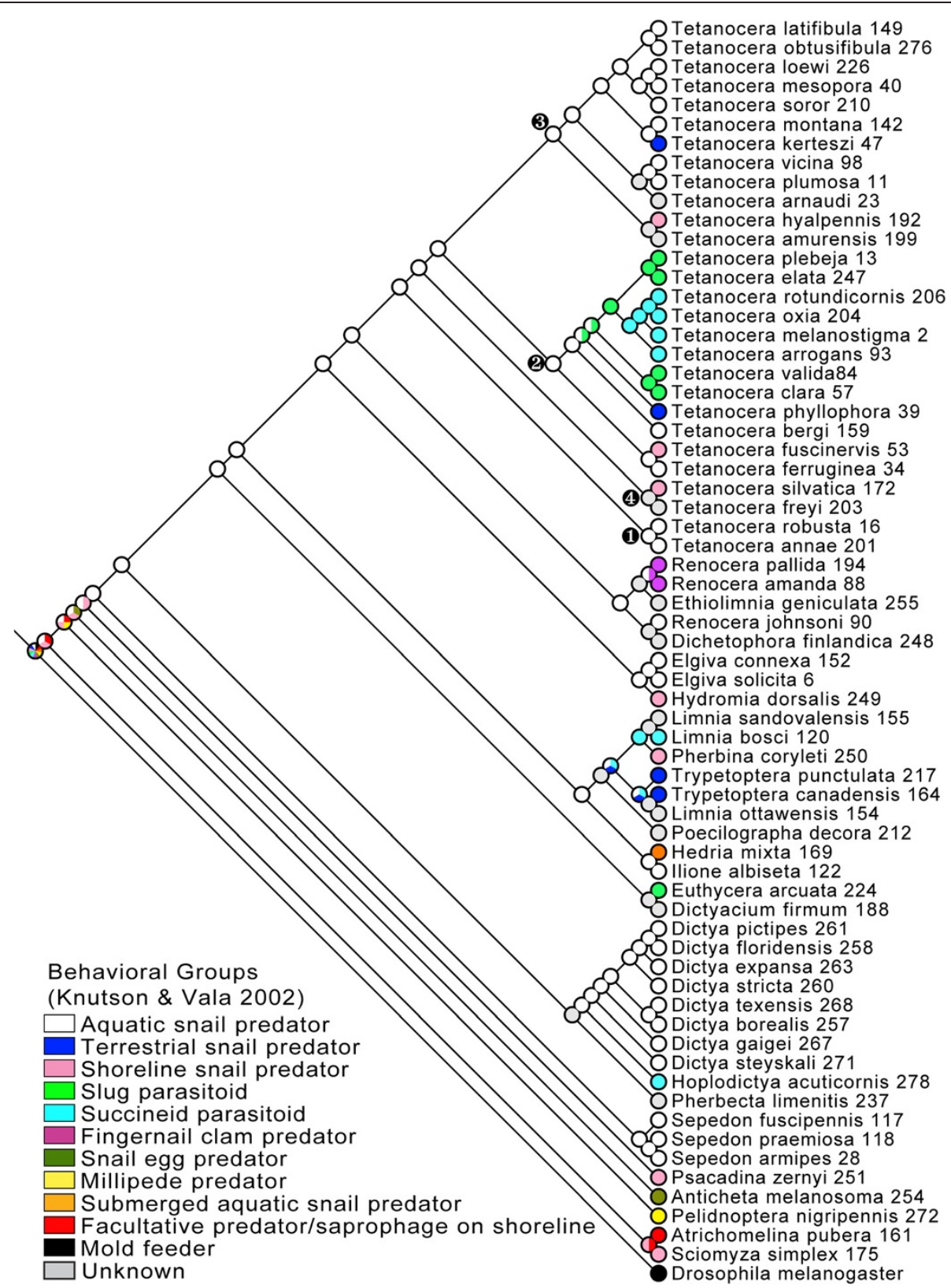

Figure 2 Maximum likelihood optimization of Knutson and Vala's [17] larval feeding groups on the topology from Figure 1 (pruned to include only one terminal per species) analyzed with Mesquite using the MK1 model of character evolution. Only character states that are statistically significantly better than the others (ancestral character state estimates with a log likelihood two or more units higher than all others) are shown in the pie charts at the nodes. A solid (one color) node indicates that state is significantly better than all other possible states. Grey indicates unknown character states. Numbers after species names are specimen numbers (Table 1).

optimization on the best ML tree). From these optimizations, we infer that $(i)$ the evolution of aquatic larvae occurred relatively early in tetanocerine phylogenesis, (ii) from this aquatic ancestor, at least 10 lineages made independent, evolutionary reversals to terrestrial existence and, during the process, made at least 15 feeding behavioral transitions, (iii) the ancestor of Tetanocera was a general predator of non-operculate snails just below the water surface and (iv) a minimum of five Tetanocera lineages made independent, evolutionary reversals to terrestrial existence during which at least seven transitions in feeding behaviors occurred. All of these transitions were judged significant by ML criteria. The optimization of larval habitat (Figure 3) demonstrates an identical aquatic to terrestrial transition pattern (as compared to Figure 2) within the Tetanocerini subsequent to the 


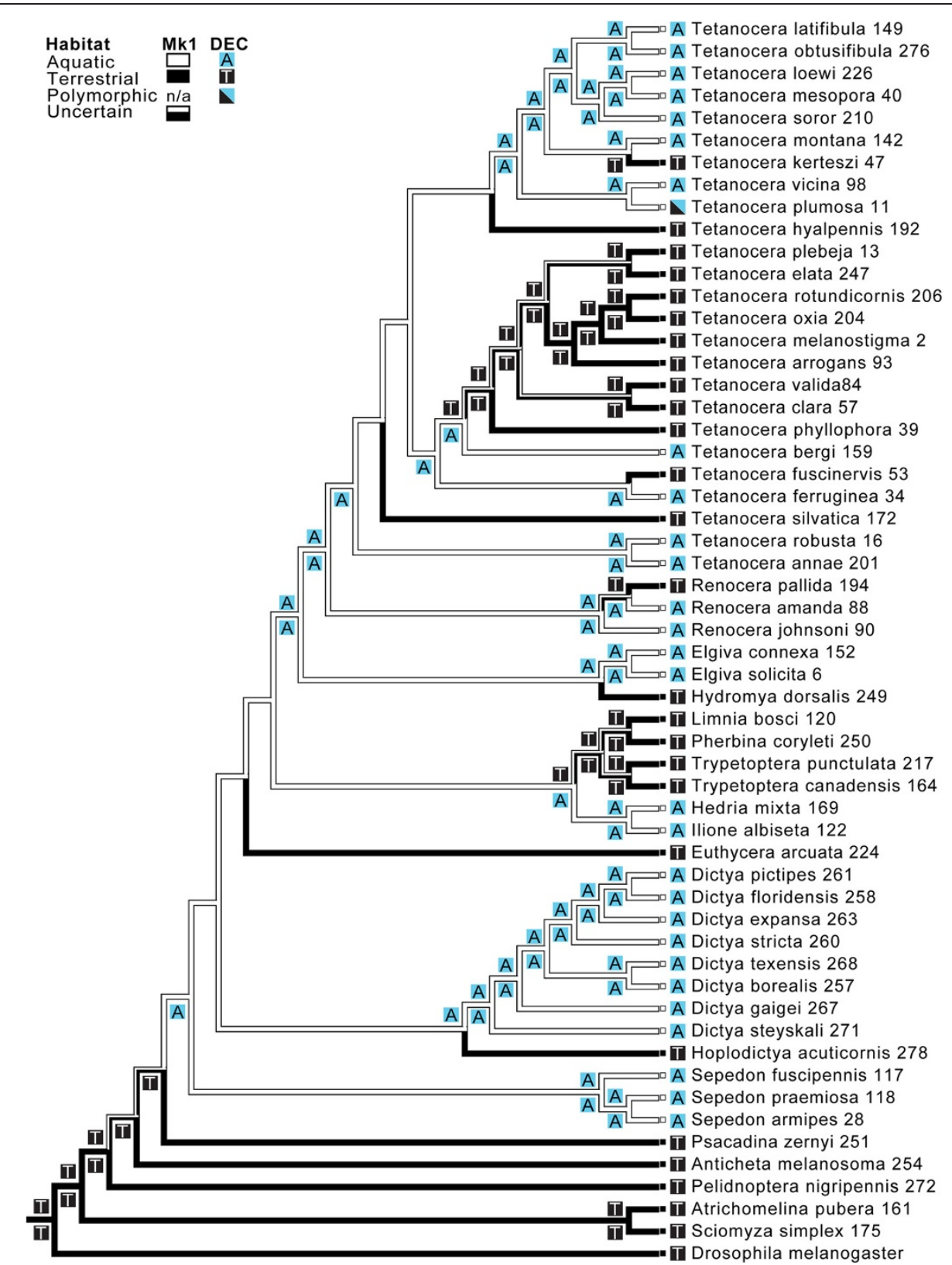

Figure 3 Maximum likelihood optimization of larval habitat on the topology from Figure 1 (pruned to include only one terminal per species) analyzed with Mesquite using the AsymmMk model of character evolution. Only character states that are statistically significantly better than the others are shown along the branches. A solid (one color) node indicates that state is significantly better than all other possible states. Numbers after species names are specimen numbers (Table 1). Lagrange-estimated ancestral charater states are denoted by blue (aquatic) and black (terrestrial) boxes. Only those nodes with a single state estimated to be significantly better than all other states are plotted. The full Lagrange output is shown in Additional file 1: Figure S5.

divergence of Sepedon. Removal of species with unknown life cycles had no significant effects on either optimization.

We also estimated the evolution of habitat changes using the dispersal-extinction-cladogenesis (DEC) model implemented in the program Lagrange [32]. We found the optimal ratio of aquatic-to-terrestrial vs. terrestrial-toaquatic transitions was between 11:1 and 13:1 which was significantly better than the null model with no bias in habitat transition rates (i.e., the global ML estimate was more than two log-likelihood units higher; Additional file 1: Table S1) and congruent with the Mesquite optimization. Therefore, the DEC model-estimated ancestral states plotted on Figure 3 are those with Lagrange set to a 12:1 ratio of aquatic-to-terrestrial vs. terrestrial-toaquatic transitions. This procedure significantly estimated a terrestrial habitat for the sciomyzid ancestral 
Table 2 Results of the likelihood-based approximately unbiased (AU), Shimodiara-Hasegawa (SH), weighted Kishino-Hasegawa (WKH), and weighted Shimodiara-Hasegawa (WSH) tests calculated using CONSEL

\begin{tabular}{|c|c|c|c|c|c|c|}
\hline \multirow[b]{2}{*}{ Constraint } & \multirow[b]{2}{*}{$-\ln \mathrm{L}$} & \multirow[b]{2}{*}{ Difference } & \multicolumn{3}{|c|}{ Test } & \multirow[b]{2}{*}{ WSH } \\
\hline & & & $\mathrm{AU}$ & $\mathrm{SH}$ & WKH & \\
\hline \multicolumn{7}{|c|}{ Tetanocera feeding group analysis (59-taxon data set) } \\
\hline Unconstrained & -38932.126 & (Best) & & & & \\
\hline Aquatic snail predators $1^{*}$ & -39212.682 & 280.556 & $p=4 e-06$ & $p<1 e-100$ & $p<1 e-100$ & $p<1 e-100$ \\
\hline Aquatic snail predators $2^{*}$ & -39252.447 & 320.321 & $p=2 e-41$ & $p<1 e-100$ & $p<1 e-100$ & $p<1 e-100$ \\
\hline Shoreline snail predators1 & -38971.538 & 39.412 & $p=0.001$ & $p=0.002$ & $p=0.002$ & $p=0.002$ \\
\hline Shoreline snail predators $2^{*}$ & -39004.527 & 72.401 & $p=1 e-07$ & $p=0.005$ & $p<1 e-100$ & $p=4 e-05$ \\
\hline Slug parasitoids & -38941.015 & 8.889 & $p=0.038$ & $p=0.631$ & $p=0.062$ & $p=0.193$ \\
\hline Terrestrial snail predators* & -39051.229 & 119.103 & $p=1 e-08$ & $p<1 e-100$ & $p<1 e-100$ & $p<1 e-100$ \\
\hline \multicolumn{7}{|c|}{ Renocerinae monophyly analysis (entire 115-taxon data set) } \\
\hline Unconstrained & -73022.049 & (Best) & & & & \\
\hline Renocerinae & -73056.937 & 34.89 & $p=0.055$ & $p=0.059$ & $p=0.059$ & $p=0.059$ \\
\hline \multicolumn{7}{|c|}{ Comparison of Bayes MAP (Figure 1) and best ML (Additional file 1: Figure S1) trees (entire data set) } \\
\hline ML tree & -72999.441 & (Best) & & & & \\
\hline Bayes MAP tree & -73005.315 & 5.875 & $p=0.377$ & $p=0.388$ & $p=0.388$ & $p=0.388$ \\
\hline
\end{tabular}

lineage, a single terrestrial-to-aquatic transition and five unambiguous aquatic-to-terrestrial transitions. Furthermore, both the DEC and Mesquite optimizations are congruent and complementary such that only one node, near the base of the tree, does not have a significant habitat estimation (Figure 3). The tetanocerine feeding behavior and habitat transitions based on the Mesquite optimizations in Figures 2 and 3 are better visualized in Figure 4.

\section{Constraint analyses}

To test hypotheses of multiple independent feeding behavior and habitat transitions, ML analyses were performed in which the monophyly of each polyphyletic Tetanocera behavioral group was constrained (Table 2). In the analyses where (1) aquatic snail predators (two variations), (2) stranded shoreline snail predators (two variations) and (3) terrestrial snail predators were constrained, all topology tests rejected their monophyly as the constrained trees yielded significantly lower loglikelihoods than the unconstrained trees (Table 2). These results support the hypothesis that there were multiple independent transitions from aquatic snail predation in the water to (1) aquatic snail predation on the shoreline and (2) terrestrial snail predation. Constraining the monophyly of slug parasitoid Tetanocera species did not result in a significantly different topology from the unconstrained tree. Finally, constraining Anticheta + Renocera to be monophyletic and further constrained to be a separate lineage outside of the currently recognized tribes produced a tree that was not significantly worse than the unconstrained tree (Table 2).

\section{Discussion}

\section{Evolutionary transitions in sciomyzid larvae}

Based on life history and larval morphological studies, Knutson \& Vala [18] concluded that "terrestrial behavior and morphology in the Tetanocerini are apomorphic features of that tribe." The present study and others support this conclusion. Wiegmann et al. [33] performed phylogenetic analyses of a comprehensive dipteran data set that yielded a monophyletic Sciomyzoidea that included eight families currently classified in the Sciomyzoidea, the Huttoninidae (elevated to family) and Conopidae, a family not previously included in the Sciomyzoidea (also see [34]). The Sciomyzidae occupies a relatively derived position within the Sciomyzoidea in the Wiegmann et al. [33] phylogeny. The only sciomyzoid taxon known to contain aquatic larvae is the Tetanocerini. Therefore, higher-level studies of Sciomyzoidea [33] support a terrestrial ancestor for Sciomyzidae and their closest relatives. The derived position of Tetanocerini within Sciomyzidae (Figures 1, 2) suggests the freshwater aquatic habit is a unique derived feature of this clade, and terrestrial behavior and morphology in the Tetanocerini are largely derived from aquatic ancestry. Our habitat optimizations (Figure 3) strongly support a terrestrial ancestor for Sciomyzidae and both Mesquite optimizations 


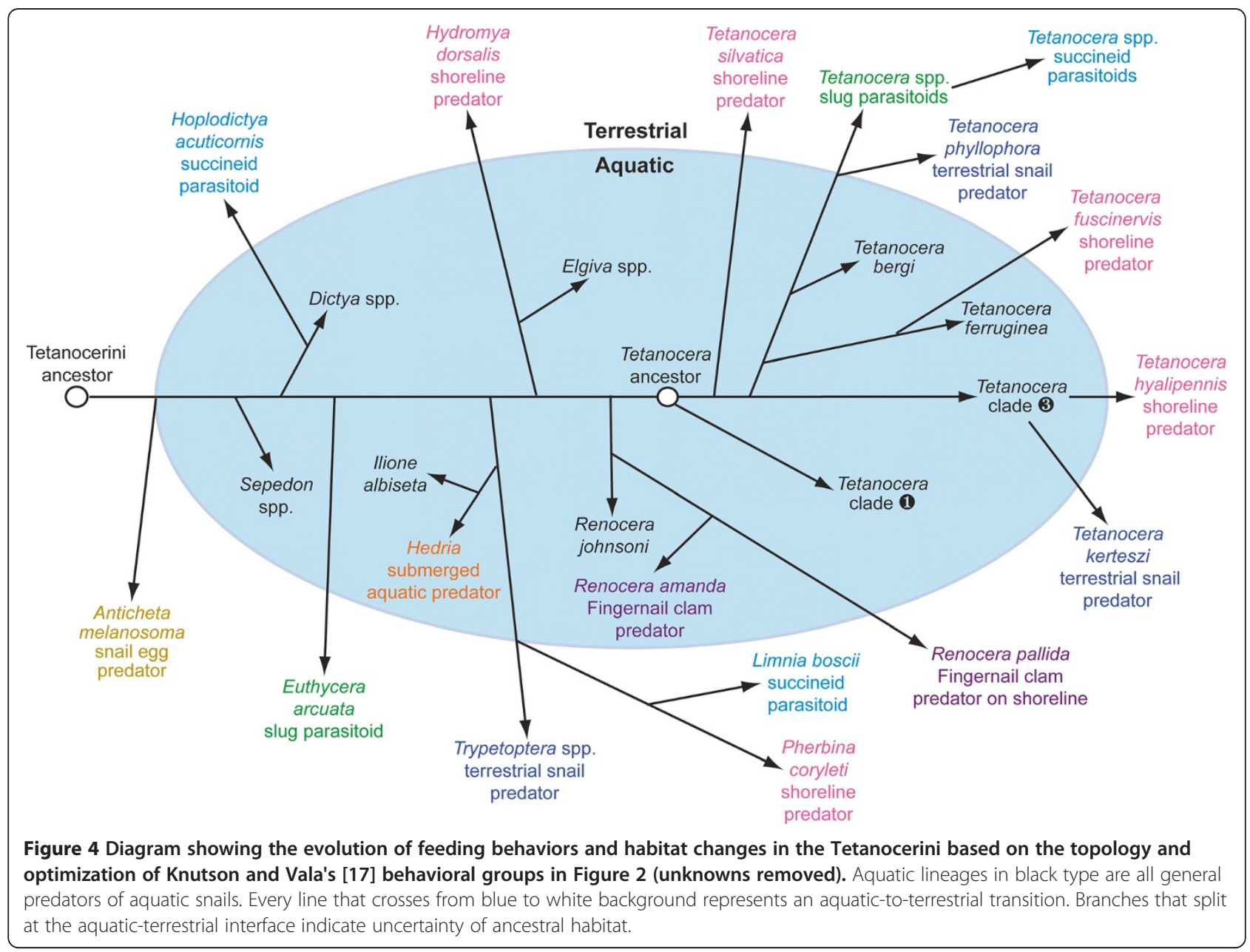

(Figures 2, 3) strongly support an aquatic ancestor for Tetanocerini minus Anticheta and Psacadina (i.e., the third basal-most Tetanocerini node). These analyses clearly demonstrate a $(i)$ sciomyzid ancestor with terrestrial larva, (ii) derived aquatic habitat for the ancestor of most Tetanocerini and ( $\mathrm{iii}$ ) secondarily derived terrestrial habitat for multiple tetanocerine lineages.

The genus Tetanocera is one of the most remarkable sciomyzid genera with respect to feeding behaviors, microhabitat and host/prey preference as its species are members of five of Knutson and Vala's [17] behavioral groups. The monophyly of Tetanocera is well-supported $(\mathrm{BI}$ PP = 1.0; ML bootstrap = 96; Figure 1, Additional file 1: Figure S1), and the ancestor to Tetanocera was strongly suported as being a predator of aquatic snails (Figure 2). From this ancestral condition, there were three independent transitions to shoreline predation on aquatic snails, two independent transitions to terrestrial snail predation, and one transition to slug parasitoidism with one lineage subsequently transitioning to succineid snail parasitoidism (Figures 2, 4). Furthermore, the monophyly of three of these behavioral groups has been rejected
(Table 2). In a more general sense, this implies that Tetanocera lineages made between three (Lagrange) and five (Mesquite) independent transitions to terrestrial habitats (Figure 3). These transitions were estimated to be statistically significant by ML (Figures 2, 3, Additional file 1: Figure S4, Additional file 1: Figure S5). In their modification of Steyskal's [35] morphology-based, Tetanocera species groups, Boyes et al. [36] stated that "the derived, terrestrial modes of [feeding] behavior have clearly arisen several times in different species groups." Our species-level phylogeny, ML optimizations and topology tests clearly support this conclusion.

\section{Sciomyzids violate trends in habitat transitions}

In their study of evolutionary aquatic-terrestrial habitat transitions, Vermeij and Dudley [14] concluded that with the exception of tetrapod vertebrates, aquatic-to-terrestrial habitat transitions are rare as compared to the reverse. However, within Diptera, more than 20 lineages have made such transitions (inferred from Figure 1 of [33]). From the present study, it can be concluded that sciomyzid lineages have made an exceptional number of 
independent transitions between aquatic and terrestrial habitats. Specifically, they have made at least one transition from terrestrial to aquatic habitats, with Mesquite estimating at least 10 lineages subsequently experiencing evolutionary reversals to terrestrial habitats (Figures 2, 3, Additional file 1: Figure S4). Additionally, the Lagrange analysis demonstrated a significant bias in the transition rate towards aquatic-to-terrestrial transitions with the overall log-likelihood maximizing near a ratio of 12:1 (Additional file 1: Table S2). Furthermore, some species in each of nine tetanocerine genera not included in our analyses (Dichetophora, Dictya, Eulimnia, Neolimnia, Perilimnia, Protodictya, Sepedon, Sepedonella, Shannonia) have terrestrial larvae [17], so it is quite likely that there have been additional aquatic-to-terrestrial transitions during the phylogenesis of the Tetanocerini. If we assume that Dichetophora, Dictya, Neolimnia, Protodictya and Sepedon are monophyletic and arose after the early tetanocerine ancestor entered the water (obviously true for three of these genera in Figure 1, Additional file 1: Figure S1), then as many as five additional aquatic-toterrestrial transitions have occurred, because each of these genera have both aquatic and terrestrial members $[17,18]$. Given that life cycle, habitat and host/prey information is available for only 240 of 540 sciomyzid species and 41 of the 61 genera [17], the actual number of independent aquatic to terrestrial habitat transitions could easily number in the 20s. Clearly, aquatic-to-terrestrial habitat transitions are strikingly common in the Sciomyzidae.

\section{Possible mechanisms for aquatic to terrestrial transitions}

Vermeij and Dudley [14] also concluded that predation intensities are generally lower in freshwater habitats than they are on land, therefore offering less biotic resistance to transitions from terrestrial to freshwater habitats than the reverse. However, our estimated evolutionary transitions within the Tetanocerini show the opposite pattern, with a 10:1 ratio of aquatic-to-terrestrial vs. terrestrialto-aquatic transitions (Figures 2, 3, 4; Additional file 1: Table S2). This raises the question of why sciomyzids are going against the trend observed by Vermeij and Dudley [14]. A portion of the answer likely lies in the larval morphological adaptations necessary for survival in each habitat. Chapman et al. [30] examined changes in four larval characters that were found to be significantly correlated with aquatic-to-terrestrial transitions in Tetanocera. They found that in each independent transition, the larvae of terrestrial lineages experienced reductions or losses in three characters associated with breathing while under water and lost pigmentation (also see [37]). This trend was observed across the Tetanocerini by Vala and Gasc [38], who found a series of reductions in the same breathing-related characters as lineages moved from aquatic to shoreline to drier terrestrial habitats. In order for a terrestrial Tetanocerini lineage to enter the water, it would have to gain those adaptations necessary to respire while mostly submerged. Therefore, the relative ease of losing aquatic adaptations versus the relative difficulty of gaining such adaptations de novo is likely one of the primary reasons that there is a much higher rate of aquatic to terrestrial habitat transitions than the reverse in sciomyzids. This significant reduction in aquatic-toterrestrial adaptive morphological constraints indicates that tetanocerine phylogenesis likely tracked some ecological pressures (e.g., increased aquatic predation and/ or increased terrestrial food availability) more accurately than did more constrained lineages.

In order for a lineage to make a successful transition to a new habitat, the members must be able to compete for and acquire resources in the new habitat [14]. Generally, it seems rather unlikely that a lineage could make multiple parallel transitions into a new habitat as the success of these transitions would typically depend upon a simultaneous adaptation to new physical conditions as well as the utilization of new food resources. However, in the case of the Tetanocerini, the intermediate nature of the damp, shoreline habitat likely played a significant role in facilitating parallel aquatic-to-terrestrial habitat transitions. Our analyses demonstrate that five of the 10 independent transitions to terrestrial habitats were to the shoreline habitat where the prey taxa are the same as their aquatic ancestors (Hydromya, Renocera, Tetanocera; Figures 2, 4). Both aquatic snails and fingernail clams occur on damp shorelines where they are either periodically stranded by receding or fluctuating waters, or in the case of snails, temporarily foraging out of the water or migrating between aquatic habitats [17]. The availability of the same food resources on the shoreline as in the water likely facilitated stepwise transitions to terrestrial existence in multiple sciomyzid lineages. Like aquatic snails, aquatic sciomyzid larvae can move onto the damp shoreline in search of their prey. However, shoreline-adapted species have lost their adaptations to breathing while under the surface of the water, and will actively swim to shore if placed in water [39]. Once a lineage has adapted to living on damp shorelines (possessing only vestiges of the adaptations to breathing while under water), they may find it more difficult to go back into the water (having to reexpress the aquatic-adapted traits) than to move to even drier habitats or switch prey type. Once accustomed to feeding on aquatic snails on terrestrial shorelines, tetanocerine lineages then are pre-adapted to preying on non-aquatic gastropods. Relative to the Tetanocerini, derived terrestrial food items include slugs, succineid (semi-terrestrial) snails and land snails. Given this evolutionary scenario, it is easy to imagine how the ancestors of dry-land terrestrial 
snail-feeding lineages like Trypetoptera, Tetanocera phyllophora and T. kerteszi used the shoreline as a stepping-stone environment facilitating a gradual movement to dry-land habitats where they became generalist predators of land snails.

A central question remains as to what selection pressures led multiple lineages of Tetanocerini to transition to terrestrial habitats with some lineages switching to prey other than aquatic pulmonate snails. Chapman et al. [30] speculated that it was a combination of (1) eliminating competition with other aquatic snail predators, (2) compensating for prolonged declines in aquatic snail populations, (3) escaping aquatic insect predators/ parasitoids and (4) the reduction and/or loss of suitable aquatic habitats due to the general drying climatic trend that took place between 65 and 5 mya (beginning of Cenozoic era to the end of the Pliocene epoch) that drove these terrestrial transitions. Wiegmann et al. [33], using the penalized likelihood method in r8s [40], estimated that the Sciomyzidae originated $\sim 30$ mya (see Fig. S3 in [33]). The oldest known fossil Tetanocerini are preserved in Baltic amber (55-24 mya [41]), and the oldest known fossil Tetanocera (although this generic assignment is questionable [41]) is from the Oligocene epoch (34-24 mya $[42,43])$. These data place Tetanocerini lineages within the general drying period mentioned above. Therefore, $(i)$ the relative ease of reducing or losing morphological characters (compared to gaining them de novo), (ii) the occurrence of the same prey on damp shorelines as occur in the water and (iii) the general drying trend all likely played key roles resulting in multiple tetanocerine lineages making independent aquatic-to-terrestrial transitions during their phylogenesis.

\section{General implications for evolutionary transitions}

The results of this study may have implications for how changes between aquatic and terrestrial habitats have occurred in other animals. Any lineage that (1) occurs in aquatic and terrestrial habitats, (2) respires the same way in aquatic and moist shoreline habitats (e.g., cuticular respiration or open tracheal system) and (3) has the same type of food available in both habitats (e.g., pulmonate snails) could show a similar pattern of multiple independent habitat transitions coincident with changes in behavioral and morphological traits. Borda \& Sidall [44] found multiple aquatic-to-terrestrial transitions in arynchobdellid leeches, and Rubinoff [45] found either multiple independent terrestrial-to-aquatic transitions or an evolutionary reversal to terrestrial habitats in one lineage of cosmopterigid moths in Hawaii. Both of these taxa fit the above criteria. Like Sciomyzidae, at least 34 other dipteran families have both aquatic and terrestrial lineages [33] and many of the larger such families have larvae that are, in general, restricted to air-breathing (e.g.,
Culicidae, Dixidae, Dolichopodidae, Stratiomyidae, Syrphidae, Tipulidae and Tabanidae [13]). Air-breathing insects have open tracheal systems and must establish contact between their spiracles and the atmosphere to respire and must therefore either remain at or come to the surface periodically. Of these families, the Tipulidae (crane flies), unlike many of the families traditionally classified in the suborder Nematocera (primitive flies with long, filamentous antennae) that probably share an aquatic ancestor, may have originated in damp terrestrial, tropical habitats [11]. Wiegmann et al.'s [33] plot of aquatic habitat on their comprehensive dipteran phylogeny indicated that most of the families of suborder Brachycera (derived flies with short antennae) with aquatic lineages were likely of terrestrial origin. Therefore, the findings presented herein should broadly interest anyone studying the evolution of aquatic and terrestrial habitat transitions and associated behavioral and morphological changes in Diptera, a group that includes over 152,000 currently named species [33]. Other lineages that fit the above criteria include oligochaete worms, pulmonate gastropods, decapods, isopods, amphipods, orbatid mites, true bugs in the infraorder Nepomorpha and beetles in the suborder Adephaga, superfamily Byrrhoidea and family Lampyridae. The results of the present study are suggestive that some lineages within these groups will also show multiple convergences on aquatic or terrestrial habits when examined with modern phylogenetic comparative methods.

\section{Conclusions}

Phylogenetic analyses of sciomyzid DNA sequences provided strong support that the Sciomyzini, Tetanocerini and Tetanocera are monophyletic (Figure 1). We significantly estimated that (i) the ancestor of the Sciomyzidae was terrestrial (Figures 2, 3), (ii) there was a single terrestrial-to-aquatic transition early in the evolution of the Tetanocerini and, subsequently, (iii) there were at least 10 independent aquatic-to-terrestrial transitions and at least 15 transitions in feeding behaviors (Figures 2, 3, 4, Additional file 1: Figure S2). The 10:1 ratio of aquatic-toterrestrial vs. terrestrial-to-aquatic transitions goes against the general trend observed in animals. We found that the ancestor to Tetanocera was aquatic and five Tetanocera lineages made independent aquatic-to-terrestrial transitions and seven independent transitions in feeding behaviors (Figures 2, 3, Additional file 1: Figure S2). Classifications of sciomyzids into ecological assemblages of species resulted in many non-monophyletic groupings (Figures 2, 3, 4, Additional file 1: Figure S2, Additional file 1: Figure S3) whose monophyly were rejected via phylogenetic constraint analyses (Table 2). Therefore, these findings strongly support our inferences of multiple independent transitions in feeding behaviors, habitats 
and prey/host usage. The damp shoreline habitat is likely a crucial transitional habitat where tetanocerine lineages that move out of the water to forage can find the same prey taxa as in the water. Once tetanocerine lineages are established on the shoreline, terrestrial molluscan taxa are available as potential food resources. From a morphological standpoint, transitioning from aquatic to terrestrial habitats is easier than the reverse, as adaptations to air-breathing just below the surface of the water are more difficult to gain than to lose. Furthermore, tetanocerine phylogenesis occurred as the Earth was going through a general drying period. These factors likely explain why so many tetanocerine lineages made secondary transitions to terrestrial environments. Finally, the results herein imply that any animal lineage that has aquatic and terrestrial members, respire the same way in both habitats and have the same type of food available in both habitats could show a similar pattern of multiple independent habitat transitions coincident with changes in behavioral and morphological traits.

\section{Materials and methods Taxon sampling}

Phylogenetic analyses were performed on DNA sequences from five genes obtained from 60 Tetanocera specimens (representing 28 species) and 53 individuals representing 21 additional genera within the Sciomyzidae (19 from the Tetanocerini (34 species)), two from the Sciomyzini (2 species) and Pelidnoptera (Phaeomyiidae) which is not currently considered to be a member of the Sciomyzidae but is thought to be its sister taxon $([23,25,26]$ but see [33]). Therefore, our analyses include $72 \%$ of Tetanocera species, $42 \%$ of the genera of Tetanocerini, and $15 \%$ of the genera of Sciomyzini. Drosophila melanogaster (Drosophilidae) was used as the outgroup in all unconstrained phylogenetic analyses. Table 1 contains a complete listing of the taxa analyzed in this study including GenBank accession numbers and the percentage of OTUs, species and genera sequenced for each gene. For 18 of the 28 Tetanocera species, multiple individuals were available and sequenced for replicate sampling purposes. Of the 29 Tetanocera species with known life cycles, 25 are examined. Of the 41 sciomyzid genera that have behavioral information known for the larvae of at least one species, at least one representative of 17 genera is included. Ten of Knutson and Vala's [17] 15 feeding groups are represented.

\section{Laboratory protocols}

Field collections of adult specimens were preserved immediately in $95 \%$ ethanol. In the laboratory, specimens were transferred to vials containing 100\% hexamethyldisilazane (Polysciences, Inc., Warrington, Pennsylvania, USA) for at least 24 hours, after which the liquid was decanted and the specimens allowed to dry under a fume hood. Prior to preparation for total DNA isolation, the head, legs, wings and abdomen of each specimen were removed from the thorax. Total DNA was isolated from each thorax, and the remaining body parts (which contain the morphological characters necessary for species determination) are stored as vouchers in 95\% ethanol at the University of Kentucky. Each specimen and associated DNA extraction was given a unique number. Species identification, collecting locality information and habitat notes were recorded in a database.

Total DNA was isolated from single individuals using Qiagen DNeasy Tissue Kits (QIAGEN Inc., Chatsworth, California, USA) following the manufacturer's animal tissue protocol. We PCR-amplified fragments of the mitochondrial cytochrome $c$ oxidase subunits I (COI) and II (COII) and $16 \mathrm{~S}$ rDNA genes, and the nuclear $28 \mathrm{~S}$ rDNA and elongation factor-1 alpha $(E F-1 \alpha)$ genes using the primer pairs listed in Table 3. Each amplicon was purified in NuSieve ${ }^{\circledR}$ GTG $^{\circledR}$ low melting temperature agarose (Lonza, Rockland, Maine, USA) and separated from the agarose with Wizard ${ }^{\circledR}$ PCR preps DNA purification system (Promega Corp., Madison, Wisconsin, USA).

Table 3 Genes / primer information used in this study

\begin{tabular}{|c|c|c|c|c|}
\hline Gene & Primer pair & References & Analyzed fragment size & Notes \\
\hline \multicolumn{5}{|c|}{ Mitochondrial loci: } \\
\hline $16 S$ & LR-N-13398 / LR-J-12887 & [105] & $426 \mathrm{bp}$ & Primer sequences identical to those of "Locust" \\
\hline \multirow[t]{3}{*}{$\mathrm{COI}$} & LCO1490 & [46] & $658 \mathrm{bp}$ & $\begin{array}{l}\text { Together, both COI primer pairs encompass } \\
\text { nearly the entire gene }\end{array}$ \\
\hline & HCO-700ME & [106] & & \\
\hline & C1-J-2183 / TL2-N-3014 & [105] & $813 \mathrm{bp}$ & \\
\hline COII & TL2-J-3034 / TK-N-3785 & [105] & $681 \mathrm{bp}$ & Amplify all of COII \\
\hline \multicolumn{5}{|c|}{ Nuclear loci: } \\
\hline 285 & $\mathrm{D} 1 \mathrm{~F} / \mathrm{D} 6 \mathrm{R}$ & [107] & 1095 bp & \\
\hline \multirow[t]{2}{*}{ Ef-1a } & ScioEF1a-F & Designed herein & $876 \mathrm{bp}$ & CAYMGDGATTTCATYAARAACATGA \\
\hline & ScioEF1a-R & & & GCRATGTGAGCGGTGTGRCAATCC \\
\hline
\end{tabular}

Analyzed fragment size is the number of base pairs remaining after primer sequences and regions of ambiguous alignment were removed. 
PCR reactions (total volume $=50 \mu \mathrm{L}$ ) consisted of $1 \mathrm{X}$ Qiagen PCR buffer, $0.2 \mathrm{mM}$ of each dNTP, $0.5 \mathrm{mM}$ of each primer, $1.25 \mathrm{U}$ of Qiagen Taq and 1-5 $\mu \mathrm{L}$ of template DNA. Cycle sequencing protocols followed Folmer et al. [46]; both strands were cycle sequenced using either end-labeled primers (Perkin Elmer AmpliCycle Sequencing Kits; Li-COR sequencer) or labeled dideoxynucleotides (ABI Big-Dye Terminator mix v. 3.0; Applied Biosystems, Foster City, California, USA; ABI sequencer). The separation of cycle sequencing reaction products was done in $3.7 \%$ and $5.5 \%$ polyacrylamide gels in LI-COR 4200 L-2 and 4200S-2 automated DNA sequencers, respectively, or Applied Biosystems 3730XL or 3730 DNA Analyzers.

\section{Phylogenetic analyses}

Bi-directional sequences were aligned using AlignIR (v. 2.0, LI-COR Biosciences, Inc., Lincoln, Nebraska, USA). Multiple sequence alignments of each gene region were produced with MAFFT [47]. The alignments of the COI, COII and EF-1 $\alpha$ sequences contained no indels, however, indels that presented alignment ambiguities were found in the sciomyzid $16 S$ and $28 S$ sequences. The GUIDANCE server [48] was used to assess confidence scores for each column in the MAFFT alignments. Columns with confidence scores $<95 \%$ were removed prior to all phylogenetic analyses. The data sets analyzed herein (including program-specific commands) have been deposited on Dryad (http://dx.doi.org/10.5061/ dryad.cb098).

Bayesian inference (BI) phylogenetic analyses were conducted on a concatenated (using MacClade v. 4.08 [49]) 4,549-character data set $(C O I=1471 \mathrm{nt}, C O I I=681$ nt, $16 S=426 \mathrm{nt}, 28 S=1095 \mathrm{nt}, E F-1 \alpha=876 \mathrm{nt})$ with MrBayes (v. 3.1.2 [50,51]). The data set contained 114 terminal taxa for which we generated sequences (including 31 terminals from Chapman et al. [30]), plus one additional terminal (D. melanogaster) whose sequences were obtained from GenBank (Table 1). The data were partitioned by gene region and codon position when appropriate (11 total partitions: three gene regions $\times$ three codon positions for the COI, COII and EF-1 $\alpha$ partitions plus a single partition each for $28 \mathrm{~S}$ and $16 \mathrm{~S}$ ) and jModeltest (v. 12.9.0 [52]) was used to determine the best-fit model for each partition (Additional file 1: Table S2). To allow each partition to have its own set of parameter estimates, revmat, tratio, statefreq, shape, and pinvar were all unlinked during the analyses. To obtain the most accurate branch length estimates possible, the option prset ratepr $=$ variable (assigns a separate branch length parameter for each partition) was employed as per the recommendations of Marshall et al. [53], who found that BI analyses of partitioned data with a global branch length parameter resulted in significantly longer overall tree length. Four 5-million generation pilot analyses (temp $=$ $0.2,0.1,0.02,0.01)$ were run to determine the optimal temperature setting to assure an appropriate acceptance rate of swaps between chains [54]. Subsequently, two independent, simultaneous BI searches were run for 160 million generations, saving a tree every 5000 generations, with four search chains each $($ temp $=0.01)$. The analysis was terminated $\sim 100$ million generations after the average standard deviation of the split frequencies fell below 0.02. The 20,000 post-burn-in trees from each run, determined by examination of the log probability of observing the data by generation plot with Tracer (v. 1.5 [55]), were used to calculate the majority rule consensus tree whose nodal support values were plotted on the BI MAP tree ( $=$ maximum a posteriori probability tree).

A maximum likelihood (ML) tree was generated using GARLI (v. 2.0 [56]) using the same partitioning scheme and model assignments as the BI analysis (above) and using the default settings except for the following: searchreps $=5$, numberofprecreductions $=20, \quad$ treerejectionthreshold $=100$. The parameter estimates from the search replicate that obtained the tree with the highest log-likelihood value were fixed in a 200-replicate ML bootstrap analysis [57] using default settings.

\section{Character optimizations}

The estimation of ancestral feeding groups, based on the BI MAP tree and best ML tree, were carried out using ML methods in Mesquite (v. 2.74 [58]). We followed the behavioral groups of Knutson and Vala [17], which are based on the most recent analysis of sciomyzid life cycles. Our data set included taxa from ten sciomyzid behavioral groups plus Pelidnoptera (Phaeomyiidae) and the outgroup (Drosophila) as $11^{\text {th }}$ and $12^{\text {th }}$ states. The Markov k-state one parameter model (MK1 [59]) was used to infer ancestral character states in the ML optimizations. We also optimized larval habitat (coded as aquatic or terrestrial) for which we utilized the Asymmetrical Markov k-state 2 parameter model (AsymmMK; available only for binary characters [60-62]) which allows forward and backward rates to be different. This model was used because the behavioral group optimization estimated a 10:1 ratio of aquatic-to-terrestrial versus terrestrial-to-aquatic transitions. To make decisions regarding the significance of ancestral character state reconstructions, we followed Pagel [63] (following Edwards [64]) who recommended that ancestral character state estimates with a log-likelihood two or more units lower than the best state estimate (decision threshold [T] set to $\mathrm{T}=2$ ) be rejected. Generally viewed as a conservative cutoff, this threshold has been used by numerous recent authors (e.g., [65-69]). The DEC model implemented in the program Lagrange [32] was also used to estimate ancestral habitats using the BI MAP tree. 
Unlike the Mesquite ML optimization which assumes instantaneous habitat transitions, Lagrange models habitat evolution along branches (i.e., over time), therefore allowing ancestors to occur in two habitats simultaneously. While apparently rare in sciomyzids, we did have one taxon (Tetanocera plumosa; see Hypothesis testing section below) that is known to occur both in aquatic and shoreline habitats. Because the Mesquite optimization suggested a 10:1 ratio of aquatic-terrestrial vs. terrestrial-aquatic transitions, we optimized this parameter in Lagrange and used a 12:1 ratio to infer ancestral habitats.

\section{Hypothesis testing}

Because many of Knutson and Vala's [17] behavioral groups within Tetanocera were not monophyletic in the unconstrained analyses, we conducted separate analyses constraining each of these groups to be monophyletic. Each resulting constrained tree was statistically compared (see below) to the unconstrained tree to test whether the monophyly of Knutson and Vala's [17] behavioral groups in Tetanocera could be rejected, thereby adding statistical support to inferences of multiple independent feeding behavior and habitat transitions. One unconstrained and six constrained analyses were done with RAxML (iMAC Pthreads-version [70,71]) using the same partitioning scheme as above under the GTR + G + I model [72]. Twenty replicate searches were done for each analysis (constrained and unconstrained) and the tree with the highest log-likelihood from each was used for topology testing (below). To assure that only topology changes within Tetanocera were the major differences between constrained and unconstrained trees, all but five outgroups were removed, leaving one individual each of D. melanogaster, Atrichomelina pubera, Anticheta melanosoma, Hoplodictya acuticornis and Limnia boscii and 54 Tetanocera terminals for which behavioral group is known (see Table 1). The non-Tetanocera taxa remaining in the analyses were chosen because each represents a major lineage in the BI MAP (maximum a-posteriori probability) tree and best ML trees and they had the lowest percentage of missing data. Behavioral groups that were not monophyletic on either the BI MAP or best ML trees were constrained in separate analyses as follows (see Table 1): Aquatic1: all Tetanocera with aquatic larvae including the facultative $T$. plumosa which can also occur on damp shorelines [73]; Aquatic2: same as Aquatic1 excluding T. plumosa; Shoreline1: all Tetanocera with larvae occurring on damp shorelines and preying on aquatic snails excluding T. plumosa; Shoreline2: same as Shoreline1 plus T. plumosa; Slug: all slug parasitoids; Terrestrials: both species predatory on terrestrial snails.
The full 115-taxon data set was used to test the monophyly of the Renocerinae, proposed by Verbeke [74] to include Renocera + Anticheta, two genera quite distantly separated in the BI and ML analyses presented herein. To constrain Renocera + Anticheta as a lineage outside of the other tribes, the Sciomyzini, Tetanocerini and Renocera + Anticheta were each constrained to be monophyletic with three separate constraint statements. Finally, this data set was also used to evaluate whether the BI MAP tree and the best ML tree were significantly different from one another.

To test for significant differences in topologies between unconstrained and constrained analyses, GARLI (v. 2.0), under the same partitioning scheme and models as the BI analysis, was used to create the sitelikelihoods file used as input for the topology-testing program CONSEL (v. $0.1 \mathrm{k}$ [75]). CONSEL was used to do the likelihood-based approximately unbiased test (AU [76]), Shimodaira-Hasegawa test (SH [77]), weighted Kishino-Hasegawa test and weighted ShimodairaHasegawa test (WKH and WSH [76]). Results of the KH test [78] were omitted due to its inappropriateness for testing a posteriori significant differences among tree topologies [79].

\section{Additional file}

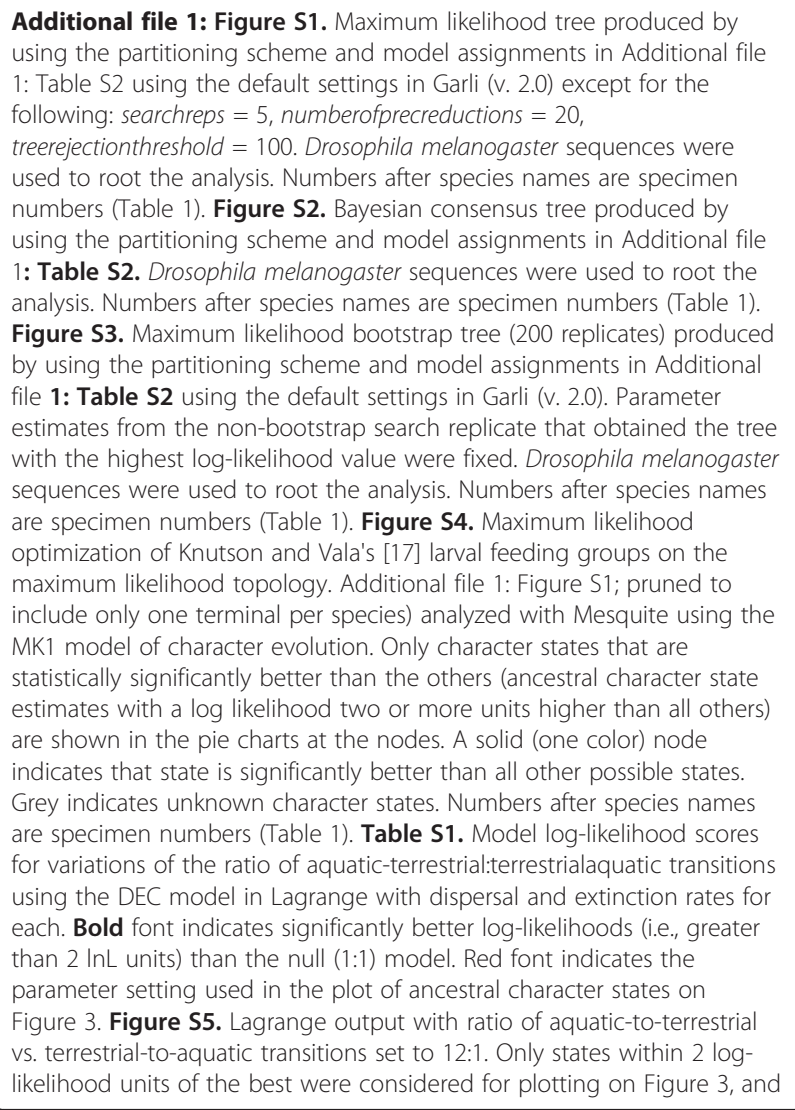

Additional file 1: Figure S1. Maximum likelihood tree produced by using the partitioning scheme and model assignments in Additional file 1: Table S2 using the default settings in Garli (v. 2.0) except for the following: searchreps $=5$, numberofprecreductions $=20$, treerejectionthreshold $=100$. Drosophila melanogaster sequences were used to root the analysis. Numbers after species names are specimen numbers (Table 1). Figure S2. Bayesian consensus tree produced by using the partitioning scheme and model assignments in Additional file 1: Table S2. Drosophila melanogaster sequences were used to root the analysis. Numbers after species names are specimen numbers (Table 1). Figure S3. Maximum likelihood bootstrap tree (200 replicates) produced by using the partitioning scheme and model assignments in Additional file 1: Table S2 using the default settings in Garli (v. 2.0). Parameter estimates from the non-bootstrap search replicate that obtained the tree with the highest log-likelihood value were fixed. Drosophila melanogaster sequences were used to root the analysis. Numbers after species names are specimen numbers (Table 1). Figure S4. Maximum likelihood optimization of Knutson and Vala's [17] larval feeding groups on the maximum likelihood topology. Additional file 1: Figure S1; pruned to include only one terminal per species) analyzed with Mesquite using the MK1 model of character evolution. Only character states that are statistically significantly better than the others (ancestral character state estimates with a log likelihood two or more units higher than all others) are shown in the pie charts at the nodes. A solid (one color) node indicates that state is significantly better than all other possible states. Grey indicates unknown character states. Numbers after species names are specimen numbers (Table 1). Table S1. Model log-likelihood scores for variations of the ratio of aquatic-terrestrial:terrestrialaquatic transitions using the DEC model in Lagrange with dispersal and extinction rates for each. Bold font indicates significantly better log-likelihoods (i.e., greater than 2 InL units) than the null (1:1) model. Red font indicates the parameter setting used in the plot of ancestral character states on Figure 3. Figure S5. Lagrange output with ratio of aquatic-to-terrestrial vs. terrestrial-to-aquatic transitions set to 12:1. Only states within 2 loglikelihood units of the best were considered for plotting on Figure 3, and 
only unambiguous states were plotted. Table S2. Gene information and evolutionary models selected by jModelTest for BI and ML phylogenetic analyses).

\section{Competing interests}

The authors declare that they have no competing interests.

\section{Author' contributions}

Research was conducted by EGC, under the overall guidance of major professors WRH and BAF at Kent State University and postdoctoral advisor $\mathrm{JDH}$ at the University of Kentucky. All advisers were integral to the development, funding and execution of all aspects of research. AAP was involved in data collection of Palaearctic specimens and contributed to the writing of the manuscript.

\section{Acknowledgments}

We thank Lita Greve-Jensen, Jere Kahanpaa, Joe Keiper, Lloyd Knutson, Steve Marshall, Wayne Mathis, Rory McDonnell, Austin Richards, Ladislav Roller, Rudolph Rozkošný and James Zanhiser for donating specimens for this project. This work was supported by NSF grant DEB-0237175 (to WRH), by a Kent State University Graduate Student Senate research grant (to EGC) and by the University of Kentucky Agricultural Experiment Station State project KY008043 (to JDH). We thank Jay Abercrombie, John Leavengood, Lloyd Knutson, and William Murphy and two anonymous reviewers for providing insightful comments on this manuscript. This is publication number 12-08-010 of the University of Kentucky Agricultural Experiment Station.

\section{Author details}

${ }^{1}$ Department of Entomology, University of Kentucky, Lexington, KY 40546, USA. 'ZZoological Institute, Russian Academy of Sciences, Universitetskaya nab. I St., Petersburg 199034, Russia. ${ }^{3}$ Evolutionary, Population, and Systematic Biology Group, Department of Biological Sciences, Cunningham Hall, Kent State University, Kent, OH 44242, USA.

Received: 27 January 2012 Accepted: 17 August 2012

Published: 10 September 2012

\section{References}

1. Stebbins GL, Hill GJC: Did multicellular plants invade the land? Am Nat 1980, 115:343-353.

2. Shear WA: The early development of terrestrial ecosystems. Nature 1991, 351:283-289.

3. Ahlberg PE, Milner AR: The origin and early diversification of tetrapods. Nature 1994, 368:507-514.

4. Retallack GJ, Feakes CR: Trace fossil evidence for Late Ordovician animals on land. Science 1987, 235:61-63.

5. Sissom WD: Systematics, biogeography, and paleontology. In The biology of scorpions. Edited by Polis GA. Stanford: Stanford University Press; 1990:65-160.

6. Rolfe WDI: Early invertebrate terrestrial faunas. In The terrestrial environment and the origin of land vertebrates. Edited by Panchen AL. London: Academic; 1980:117-157.

7. Shear WA, Gensel PG, Jeram AJ: Fossils of large terrestrial arthropods from the Lower Devonian of Canada. Nature 1996, 384:555-557.

8. Humphreys GS: Evolution of terrestrial burrowing invertebrates. In Advances in Regolith. Edited by Roach IC. LEME: CRC; 2003:211-215.

9. Poinar GO: The evolutionary history of nematodes as revealed in stone, amber and mummies. Leiden; Boston: Brill; 2011 [Nematology Monographs and Perspectives, vol 9].

10. Labandeira CC, Beall BS, Hueber FS: Early insect diversification: evidence from a Lower Devonian bristletail from Québec. Science 1988, 242:913-916.

11. Pritchard G, McKee MH, Pike EM, Scrimgeour GJ, Sloty J: Did the first insects live in water or in air? Biol J Linnean Soc 1993, 49:31-44.

12. D'Haese CA: Were the first springtails semi-aquatic? A phylogenetic approach by means of $28 \mathrm{~s}$ rDNA and optimization alignment. $P$ Roy Soc Lond B Bio 2002, 269:1143-1151.

13. Merritt RW, Cummins KW, Berg MB: An Introduction to the Aquatic Insects of North America. Kendall/Hunt. 2008.
14. Vermeij GJ, Dudley R: Why are there so few evolutionary transitions between aquatic and terrestrial ecosystems? Biol I Linnean Soc 2000 70:541-554.

15. Chase JM: Are there real differences among aquatic and terrestrial food webs? Tree 2000, 15:408-412.

16. Shurin JB, Gruner DS, Hillebrand H: All wet or dried up? Real differences between aquatic and terrestrial food webs. Proc R Soc B 2006, 273:1-9.

17. Knutson LV, Vala J-C: Biology of Snail-Killing Sciomyzidae Flies. Cambridge: Cambridge University Press; 2011.

18. Knutson LV, Vala J-C: An evolutionary scenario of Sciomyzidae and Phaeomyiidae (Diptera). Ann Soc Entomol Fr 2002, 38:145-162.

19. Coupland JB, Barker GM: Diptera as predators and parasitoids of terrestrial gastropods, with emphasis on Phoridae, Calliphoridae, Sarcophagidae, Muscidae and Fanniidae (Diptera, Brachycera, Cyclorrhapha). In Natural Enemies of Terrestrial Molluscs. Edited by Barker GM. Oxfordshire: CABl; 2004:85-158.

20. Ferrar P: Sciomyzidae. In A guide to the breeding habits and immature stages of Diptera Cyclorrhapha (part 1: text). Leiden and Copenhagen: E. J. Brill/Scandanavian Science Press; 1987:815-827.

21. Berg CO, Knutson LV: Biology and systematics of the Sciomyzidae. Ann Rev Entomol 1978, 23:239-258.

22. Greathead DJ: Arthropod natural enemies of bilharzia snails and the possibilities for biological control. Biocontr News Info, CIBC. 1981, 2:197-202.

23. Barker GM, Knutson LV, Vala J-C, Coupland JB, Barnes JK: Overview of the biology of marsh flies (Diptera: Sciomyzidae), with special reference to predators and parasitoids of terrestrial gastropods. In Natural Enemies of Terrestrial Molluscs. Edited by Barker GM. Oxfordshire: CABl; 2004:159-226.

24. Wagner R, Bartak M, Borkent A, Courtney G, Goddeeris B, Haenni J-P, Knutson LV, Pont A, Rotheray GE, Rozkošný R, Sinclair B, Woodley N, Zatwarnicki T, Zwick P: Global diversity of dipteran families (Insecta Diptera) in freshwater (excluding Simulidae, Culicidae, Chironomidae, Tipulidae and Tabanidae). Hydrobiologia 2008, 595:489-519.

25. Marinoni L, Mathis WN: A cladistic analysis of Sciomyzidae Fallen (Diptera). Proc Entomol Soc Wash 2000, 113:162-209.

26. Griffiths GCD: The phylogenetic classification of Diptera. Cyclorrhapha with special reference to the structure of the male postabdomen. The Haque: Junk; 1972.

27. Berg CO, Foote BA, Neff SE: Evolution of predator-prey relationships in snail-killing sciomyzid larvae (Diptera). Bulletin of the American Malacological Union Inc. 1959, 25:10-13.

28. Foote BA, Neff SE, Berg CO: Biology and immature stages of Atrichomelina pubera (Diptera: Sciomyzidae). Ann Entomol Soc Am 1960, 53:192-199.

29. Steyskal GC: The subfamilies of Sciomyzidae of the world (Diptera: Acalyptratae). Ann Entomol Soc Am 1965, 58:593-594.

30. Chapman EG, Foote BA, Malukiewicz J, Hoeh WR: Parallel evolution of larval morphology and habitat in the snail-killing fly genus Tetanocera. J Evol Biol 2006, 19:1459-1474.

31. Rozkošný R: A Review of the Palaearctic Sciomyzidae (Diptera). Folia Facultatis Scientiarum Naturalium Universitatis Purkynianae Brunensis. 1987.

32. Ree RH, Smith SA: Maximum likelihood inference of geographic range evolution by dispersal, local extinction, and cladogenesis. Syst Biol 2008, $57: 4-14$.

33. Wiegmann BM, Trautwein MD, Winkler IS, Barr NB, Kim J-W, Lambkin C, Bertonea MA, Cassel BK, Keith MKM, Heimberg AM, Wheeler BM, Peterson KJ, Pape T, Sinclair BJ, Skevington JH, Blagoderov V, Caravas J, Kutty SN, Schmidt-Ottm U, Kampmeiern GE, Thompson FC, Grimaldi DA, Beckenbach AT, Courtney GW, Friedrichk M, Meier R, Yeates DK: Episodic radiations in the fly tree of life. Proc Nat Acad Sci 2011, doi:10.1073/pnas.1012675108.

34. Gibson JF, Skevington JH, Kelso S: Placement of Conopidae (Diptera) within Schizophora based on mtDNA and nrDNA gene regions. Molec Phylogenet Evol 2010, 56:91-103.

35. Steyskal GC: The American species of the genus Tetanocera Duméril (Diptera). Pap Mich Acad Sci Arts Lett 1959, 44:55-91.

36. Boyes JW, Knutson LV, van Brinck JM: Further cytotaxonomic studies of Sciomyzidae with description of a new species, Dichetophora boyesi Steyskal (Diptera: Acalyptratae). Genetica 1972, 43:344-365.

37. Knutson LV, Rozkošný R, Berg CO: Biology and immature stages of Pherbina and Psacadina (Diptera: Sciomyzidae). Acta Scientiarum Naturalium Academiae Scientiarum Bohemicae Brno 1975, 9:1-38. 
38. Vala J-C, Gasc C: Ecological adaptations and morphological variation in the posterior disc of larvae of Sciomyzidae (Diptera). Can J Zool 1990, 68:517-521.

39. Knutson LV: Biology and Immature Stages of Snail-killing Flies of Europe Diptera: Sciomyzidae). PhD Thesis: Cornell University; 1963.

40. Sanderson MJ: Estimating absolute rates of molecular evolution and divergence times: a penalized likelihood approach. Molec Biol Evol 2002, 19:101-109.

41. Hennig W: Die Acalyptratae des baltischen Bernsteins und ihre Bedeutung für die Erforschung der phylogenetischen Entwicklung dieser Dipteren-Gruppe. Stuttg Beitr Naturkd 1965, 145:1-215.

42. Théobald N: Les insectes fossiles des terrains oligocènes de France. Memoires de la Societe des Sciences de Nancy 1937, 2:1-473.

43. Förster B: Die Insekten des "Plattigen Steinmergels" von Brunstatt. Abh Geol Spez.-Karte Elsass-Lotheringen 1891, 3:333-594.

44. Borda E, Siddall ME: Arhynchobdellida (Annelida: Oligochaeta: Hirudinida): phylogenetic relationships and evolution. Molec Phylogenet Evol 2004, 30:213-225

45. Rubinoff D: Phylogeography and ecology of an endemic radiation of Hawaiian aquatic case-bearing moths (Hyposmocoma: Cosmopterigidae). Phil Trans R Soc B 2008, 363:3459-3465.

46. Folmer O, Black $M$, Hoeh WR, Lutz R, Vrijenhoek R: DNA primers for amplification of mitochondrial cytochrome $c$ oxidase subunit I from diverse metazoan invertebrates. Mol Mar Biol Biotechnol 1994, 3:294-299.

47. Katoh K, Kuma K, Toh H, Miyata T: MAFFT version 5: improvement in accuracy of multiple sequence alignment. Nucleic Acids Res 2006, 33:511-518.

48. Penn O, Privman E, Ashkenazy H, Landan G, Graur D, Pupko T: GUIDANCE: a web server for assessing alignment confidence scores. Nucleic Acids Res 2010, 38:W23-W28. Web Server issue.

49. Maddison WP, Maddison DR: MacClade: Analysis of Phylogeny and Character Evolution. Sunderland: Sinauer Assoc., Inc.; 2000.

50. Huelsenbeck JP, Ronquist F: MRBAYES: Bayesian inference of phylogenetic trees. Bioinformatics 2001, 17:754-755.

51. Ronquist F, Huelsenbeck JP: MrBayes 3: Bayesian phylogenetic inference under mixed models. Bioinformatics 2003, 19:1572-1574.

52. Posada D: jModelTest: phylogenetic model averaging. Molec Biol Evol 2008, 25:1253-1256.

53. Marshall DC, Simon C, Buckley TR: Accurate branch length estimation in partitioned Bayesian analyses requires accommodation of amongpartition rate variation and attention to branch length priors. Syst Biol 2006, 55:992-1003.

54. Ronquist F, van der Mark P, Huelsenbeck JP: Bayesian phylogenetic analysis using MrBayes: Practice. In The Phylogenetic Handbook: A practical approach to phylogenetic analysis and hypothesis testing. 2nd edition. Edited by Lemey P, Salemi M, Vandamme A-E. Cambridge: Cambridge University Press; 2009:210-266.

55. Rambaut A, Drummond AJ: Tracer v 1.5. 2009. http://tree.bio.ed.ac.uk/ software/tracer/.

56. Zwickl DJ: Genetic algorithm approaches for the phylogenetic analysis of large biological sequence datasets under the maximum likelihood criterion. PhD dissertation: The University of Texas at Austin; 2006. http://garli.nescent.org.

57. Felsenstein J: Confidence limits on phylogenies: An approach using the bootstrap. Evolution 1985, 39:783-791

58. Maddison WP, Maddison DR: Mesquite: a modular system for evolutionary analysis. Version 2.74. 2010. http://mesquiteproject.org.

59. Lewis PO: A likelihood approach to estimating phylogeny from discrete morphological character data. Syst Biol 2001, 50:913-925.

60. Pagel M: Inferring evolutionary processes from phylogenies. Zoologica Scripta 1997, 26:331-348.

61. Mooers $A O$, Schluter $\mathrm{D}$ : Reconstructing ancestor states with maximum likelihood: support for one- and two-rate models. Syst Biol 1999, 48:623-633.

62. Maddison WP: Confounding asymmetries in evolutionary diversification and character change. Evolution 2006, 60:1743-1746.

63. Pagel M: The maximum likelihood approach to reconstructing ancestral character states on phylogenies. Syst Biol 1999, 48:612-622.

64. Edwards AWF: Likelihood. Cambridge: Cambridge University Press; 1972.

65. Moczek AP, Cruickshank TE, Shelby A: When ontogeny reveals what phylogeny hides: Gain and loss of horns during development and evolution of horned beetles. Evolution 2006, 60:2329-2341.
66. Fernandez AA, Morris MR: Sexual selection and trichromatic color vision in primates: Statistical support for the preexisting-bias hypothesis. Am Nat 2007, 170:10-20.

67. Murphy NP, Carey D, Castro LR, Dowton M, Austin AD: Phylogeny of the platygastroid wasps (Hymenoptera) based on sequences from the $18 \mathrm{~S}$ rRNA, 28S rRNA and cytochrome oxidase I genes: implications for the evolution of the ovipositor system and host relationships. Biol J Linnean Soc 2007, 91:653-669.

68. Koepfli KP, Deere KA, Slater GJ, Begg C, Begg K, Grassman L, Lucherini M, Veron G, Wayne RK: Multigene phylogeny of the Mustelidae: Resolving relationships, tempo and biogeographic history of a mammalian adaptive radiation. BMC Biol 2008, 6:10

69. Weeks SC, Chapman EG, Rogers DC, Senyo DM, Hoeh WR: Evolutionary transitions among dioecy, androdioecy and hermaphroditism in limnadiid clam shrimp (Branchiopoda: Spinicaudata). J Evol Biol 2009, 22:1781-1799.

70. Stamatakis A: RAxML-VI-HPC: maximum likelihood-based phylogenetic analyses with thousands of taxa and mixed models. Bioinformatics 2006, 22:2688-2690.

71. Ott M, Zola J, Aluru S, Stamatakis A: Large-scale maximum likelihoodbased phylogenetic analysis on the IBM BlueGene/L. In Proceedings of the 2007 ACM/IEEE conference on supercomputing. 2007. ISBN: 978-1-59593-764-3.

72. Rodriguez F, Oliver JL, Marin A, Medina JR: The general stochastic model of nucleotide substitution. J Theor Biol 1990, 142:485-501.

73. Foote BA: Biology and immature stages of snail-killing flies belonging to the genus Tetanocera (Diptera: Sciomyzidae). V. Biology of three additional species having larvae that prey on aquatic pulmonate snails. Ann Carnegie Mus 2011, 79:125-130.

74. Verbeke J, de Witte MGF: Fasc. 66. Sciomyzidae (Diptera Cyclorrhapha). In Exploration du Parc National Albert. Brussels: Hayez; 1950:1-37. 1933-35.

75. Shimodaira H, Hasegawa M: CONSEL: for assessing the confidence of phylogenetic tree selection. Bioinformatics 2001, 17:1246-1247.

76. Shimodaira $\mathrm{H}$ : An approximately unbiased test of phylogenetic tree selection. Syst Biol 2002, 51:492-508.

77. Shimodaira H, Hasegawa M: Multiple comparisons of log-likelihoods with applications to phylogenetic inference. Molec Biol Evol 1999, 16:1114-1116

78. Kishino $\mathrm{H}$, Hasegawa M: Evaluation of the maximum likelihood estimate of the evolutionary tree topologies from DNA sequence data, and the branching order of the Hominoidea. J Molec Evol 1989, 29:170-179.

79. Goldman N, Anderson JP, Rodrigo RG: Likelihood-based tests of topologies in phylogenetics. Syst Biol 2000, 49:652-670.

80. Lindsay SL: Food preferences of Drosophila larvae. Am Nat 1958 92:279-285.

81. Bailey PT: The millipede parasitoid Pelidnoptera nigripennis (F.) (Diptera: Sciomyzidae) for the biological control of the millipede Ommatoiulus moreleti (Lucas) (Diplopoda: Julida: Julidae) in Australia. B Entomol Res 1989, 79:381-391.

82. Knutson LV: Life cycles of snail-killing flies: Pherbellia griseicollis, Sciomyza dryomyzina, S. simplex, and S. testacea (Diptera: Sciomyzidae). Entomol Scand 1987, 18:383-391.

83. Knutson LV, Abercrombie J: Biology of Antichaeta melanosoma (Diptera: Sciomyzidae), with notes on parasitoid Ichneumonidae (Hymenoptera). Proc Entomol Soc Wash 1977, 79:111-125.

84. Valley K, Berg CO: Biology, immature stages, and new species of snail killing Diptera of the genus Dictya (Sciomyzidae). Search Agriculture, Entomology 1977, 18:1-44.

85. McLauglin RE, Dame DA: Rearing Dictya floridensis (Diptera: Sciomyzidae) in a continuously producing colony and evaluation of larvae food sources. J Med Entomol 1989, 26:522-527.

86. Knutson LV, Berg CO: Biology and immature stages of snail-killing flies: the genus Elgiva (Diptera: Sciomyzidae). Ann Entomol Soc Am 1964, 57:173-192.

87. Knutson LV: Biology of snail-killing flies in Sweden (Diptera: Sciomyzidae). Entomol Scand 1970, 1:307-314.

88. Foote BA: Biology of Hedria mixta (Diptera: Sciomyzidae). Ann Entomol Soc Am 1971, 64:931-941. 
89. Knutson LV, Berg CO: Biology and immature stages of a snail-killing fly, Hydromya dorsalis (Fabricius) (Diptera: Sciomyzidae). Proc R Entomol Soc A 1963, 38:45-58.

90. Hope Cawdery MJ, Lindsay W: Observations on the decline of the snail (Lymnaea truncata, Linn.) and the liver fluke (Fasciola hepatica, Linn.) on reclaimed western blanket peat and its possible relationship to predation by Hydromya dorsalis (Fab.). Proc R Ir Acad Sem Biol Cont 1977, Seminar on Biological Control:161-169.

91. Knutson LV, Berg CO: Biology and immature stages of malacophagous Diptera of the genus Knutsonia Verbeke (Sciomyzidae). Institut royal des Sciences naturelles de Belgique, Bulletin 1967, 43:160.

92. Lindsay W, McDonnell RJ, Williams CD, Knutson L, Gormally MJ: Biology of the snail-killing fly llione albiseta (Scopoli, 1763) (Diptera: Sciomyzidae), Studia Dipterol 2009, 16:245-307.

93. Foote BA: Biology and larval feeding habits of three species of Renocera (Diptera: Sciomyzidae) that prey on fingernail clams (Mollusca: Sphaeriidae). Ann Entomol Soc Am 1976, 69:121-133.

94. Horsáková J: Biology and immature stages of the clam-killing fly, Renocera pallida (Diptera: Sciomyzidae). Eur J Entomol 2003, 100:143-151.

95. Neff SE, Berg CO: Biology and immature stages of malacophagous Diptera of the genus Sepedon (Sciomyzidae). Virg Agric Exp Sta Bull 1966, 566:1-113.

96. Foote BA: Biology and immature stages of snail-killing flies belonging to the genus Tetanocera (Insecta: Diptera: Sciomyzidae) 3. Life histories of the predators of aquatic snails. Ann Carnegie Mus 1999, 68:151-174.

97. Trelka DG, Foote BA: Biology of slug-killing Tetanocera (Diptera: Sciomyzidae). Ann Entomol Soc Am 1970, 63:877-895.

98. Foote BA: Biology and immature stages of snail-killing flies belonging to the genus Tetanocera (Diptera: Sciomyzidae). IV. Life histories of predators of land snails and slugs. Ann Carnegie Mus 2008, 77:301-312

99. Knutson LV, Stephenson JW, Berg CO: Biology of a slug-killing fly, Tetanocera elata (Diptera: Sciomyzidae). Proceedings of the Malacological society of London 1965, 36:213-220.

100. Foote BA: Biology and immature stages of snail-killing flies belonging to the genus Tetanocera (Insecta: Diptera: Sciomyzidae). 1. Introduction and life histories of predators of shoreline snails. Ann Carnegie Mus 1996a, 65:1-12.

101. Foote BA: Biology and immature stages of snail-killing flies belonging to the genus Tetanocera (Insecta: Diptera: Sciomyzidae). 2. Life histories of predators of snails of the family Succineidae. Ann Carnegie Mus 1996b, 65:153-166.

102. Bhatia ML, Keilinm D: On a new case of parasitism of snail (Vertigo genesii Gredl.) by a dipterous larva. Parasitology 1937, 29:399-408.

103. Foote BA: Biology and immature stages of the snail-killing flies belonging to the genus Tetanocera (Diptera: Sciomyzidae). PhD Thesis: Cornell University; 1961.

104. Vala J-C: Description des stades larvaires et donnees sur la biologie de Trypetoptera punctulata (Diptera, Sciomyzidae). Ann Soc Entomol France 1986, 22:67-77.

105. Simon C, Frati F, Beckenbach A, Crespi B, Liu H, Flook P: Evolution, weighting, and phylogenetic utility of mitochondrial gene sequences and a compilation of conserved polymerase chain reaction primers. Ann Entomol Soc Am 1994, 87:651-701.

106. Breton S, Burger G, Stewart DT, Blier PU: Comparative analysis of gender-associated complete mitochondrial genomes in marine mussels (Mytilus spp.). Genetics 2006, 172:1107-1119.

107. Park J-K, O'Foighil D: Sphaeriid and corbiculid clams represent separate heterodont bivalve radiations into freshwater environments. Mol Phylogenet Evol 2000, 14:75-88.

doi:10.1186/1471-2148-12-175

Cite this article as: Chapman et al: Widespread and persistent invasions of terrestrial habitats coincident with larval feeding behavior transitions during snail-killing fly evolution (Diptera: Sciomyzidae). BMC Evolutionary Biology 2012 12:175.

\section{Submit your next manuscript to BioMed Central and take full advantage of:}

- Convenient online submission

- Thorough peer review

- No space constraints or color figure charges

- Immediate publication on acceptance

- Inclusion in PubMed, CAS, Scopus and Google Scholar

- Research which is freely available for redistribution 